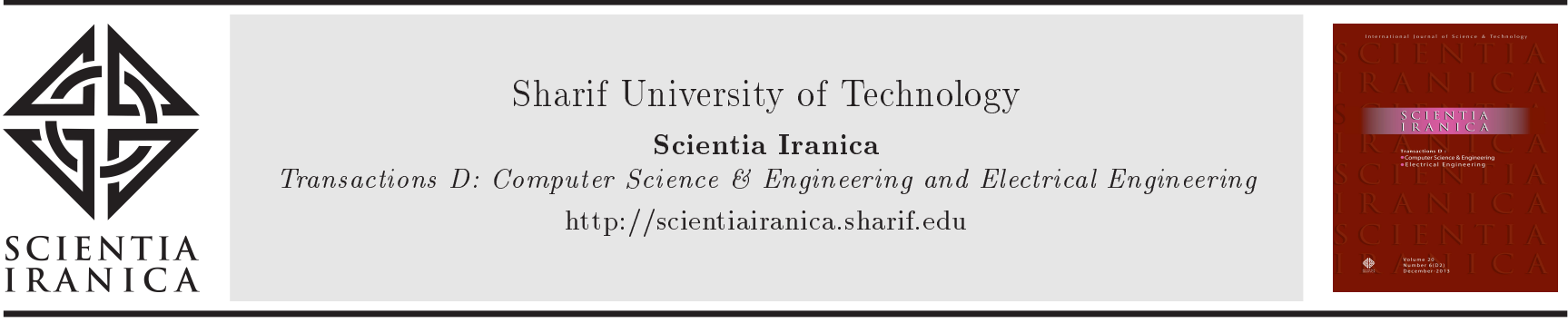

\title{
An optimal radiation pattern synthesis and correction of mutually coupled circular dipole antenna array
}

\author{
A. Das ${ }^{*, 1}$, D. Mandal, and R. Kar \\ Department of Electronics and Communication Engineering, NIT Durgapur, West Bengal, India, 713209.
}

Received 10 June 2019; received in revised form 23 January 2020; accepted 11 May 2020

\author{
KEYWORDS \\ Circular dipole \\ antenna array; \\ Mutual coupling; \\ Parametric \\ assimilation \\ technique; \\ Directivity; \\ Grey wolf \\ optimization.
}

\begin{abstract}
This paper proposes a fundamental approach to radiation pattern correction of the mutually coupled Circular Dipole Antenna Array (CDAA) using parametric assimilation technique. The effect of mutual coupling is an indispensable part of any practical design issue of the antenna array. Many analytical and numerical techniques were put forward in the past few decades for the calculation, compensation, and reduction of mutual coupling effect. This paper shows an accurate method for mutual coupling correction using a recently proposed technique called parametric assimilation technique, where the values of mutual impedance are calculated and assimilated with the values of the desired radiation pattern. The proposed technique is cost-effective, less complicated, and easy to implement while achieves better performance for mutually coupled circular dipole antenna array synthesis. Grey Wolf Optimization (GWO) algorithm is a state-ofthe-art stochastic algorithm applied here to find the optimal values of the current excitation weights and the inter-element spacing between each element of the CDAA for the desired, uncorrected, and corrected far-field radiation pattern synthesis. PSO and DE optimizationbased statistical results are also reported to compare the results obtained by using GWO algorithm to confirm the outstanding performance of GWO algorithm-based design.
\end{abstract}

(C) 2022 Sharif University of Technology. All rights reserved.

\section{Introduction}

The design accuracy of an antenna array has a crucial role in the wireless communication system. Several types of research proposals on the antenna array designs have been placed in the past few decades for the improvement of the radiation pattern characteristics. The problem of mutual coupling is an inseparable

1. Present address: Department of Electronics and Communication Engineering, HIT Haldia, India, 721657.

*. Corresponding author.

E-mail addresses: avishek.uit0408@gmail.com (A.Das); durbadal.bittu@gmail.com (D. Mandal);

rajibkarece@gmail.com ( $R$. Kar)

doi: $10.24200 /$ sci. 2020.53745 .3393 part of all the practical antenna array design issues. In terms of practical design, the minimization of the physical size of the antenna array is desirable, which leads to an increase in the mutual coupling effect between the elements of the array [1-3]. The performance of the antenna array degrades severely due to the presence of mutual coupling among the array elements, which causes an impedance mismatch, deviation in the radiation pattern, distortion, etc. A significant number of research works have been done for the optimal radiation pattern synthesis of the Circular Antenna Array (CAA) [4-10] using various optimization techniques. However, the correction of mutual coupling affected erred radiation pattern in the form of the desired radiation pattern is hardly found. Nowadays, most of the research proposals on 
the optimization of antenna arrays are not suitable for practical applications as they do neglect the mutual coupling effect.

In this paper, the mutual coupling affected erred pattern of the CDAA is corrected by using the parametric assimilation technique [11]. In the parametric assimilation technique, the antenna array parameters are calculated by applying the concept of two-port network analysis, which is extended up to $n$-port.

Majority of the research works mainly focus on the mutual impedance for mutual coupling reduction and compensation [12-17]. In this paper, the mutual coupling effect of CDAA radiation pattern is corrected by using the parametric assimilation technique, which performs the matching and assimilation on the parameters like current excitation weights and inter-element spacing. To establish the method of parametric assimilation technique, 8- and 10-element CDAAs are considered in this paper.

The rest of the paper is arranged as follows. Section 2 presents an overview of the parametric assimilation technique. Section 3 shows the design equation and the evaluation of the cost function for CDAA. Section 4 describes GWO algorithm briefly. Section 5 shows the comparison, simulation, and statistical-based results obtained by using different algorithms and fullwave simulation-based results. Section 6 presents the conclusion of the paper.

\section{Overview of the parametric assimilation technique}

The name parametric assimilation technique is derived from its performance for matching and assimilation of the antenna array parameters like current excitation weights and inter-element spacing, as shown in a flowchart in Figure 1. Parametric assimilation technique consists of two parallel processes: one is to generate the desired pattern and the other one is to calculate the position matrix. The desired pattern is the radiation pattern of an ideal antenna array. The parameter values are extracted and assimilated with other matrix elements, which are required for mutual coupling calculation. The position matrix is formed initially with the physical parameters like inter-element spacing and number of elements. These physical parameters are required to determine the location information for the calculation of inter-element spacing.

The next step, after the calculation of the distance matrix, is to calculate the impedance matrix and the matrix of mutual currents. The parametric assimilation technique is applied based on the network analysis of two different currents known as the initial current and the final current. Typically, the current from the ideal antenna array is considered as the initial or feed currents. The initial/feed current undergoes the

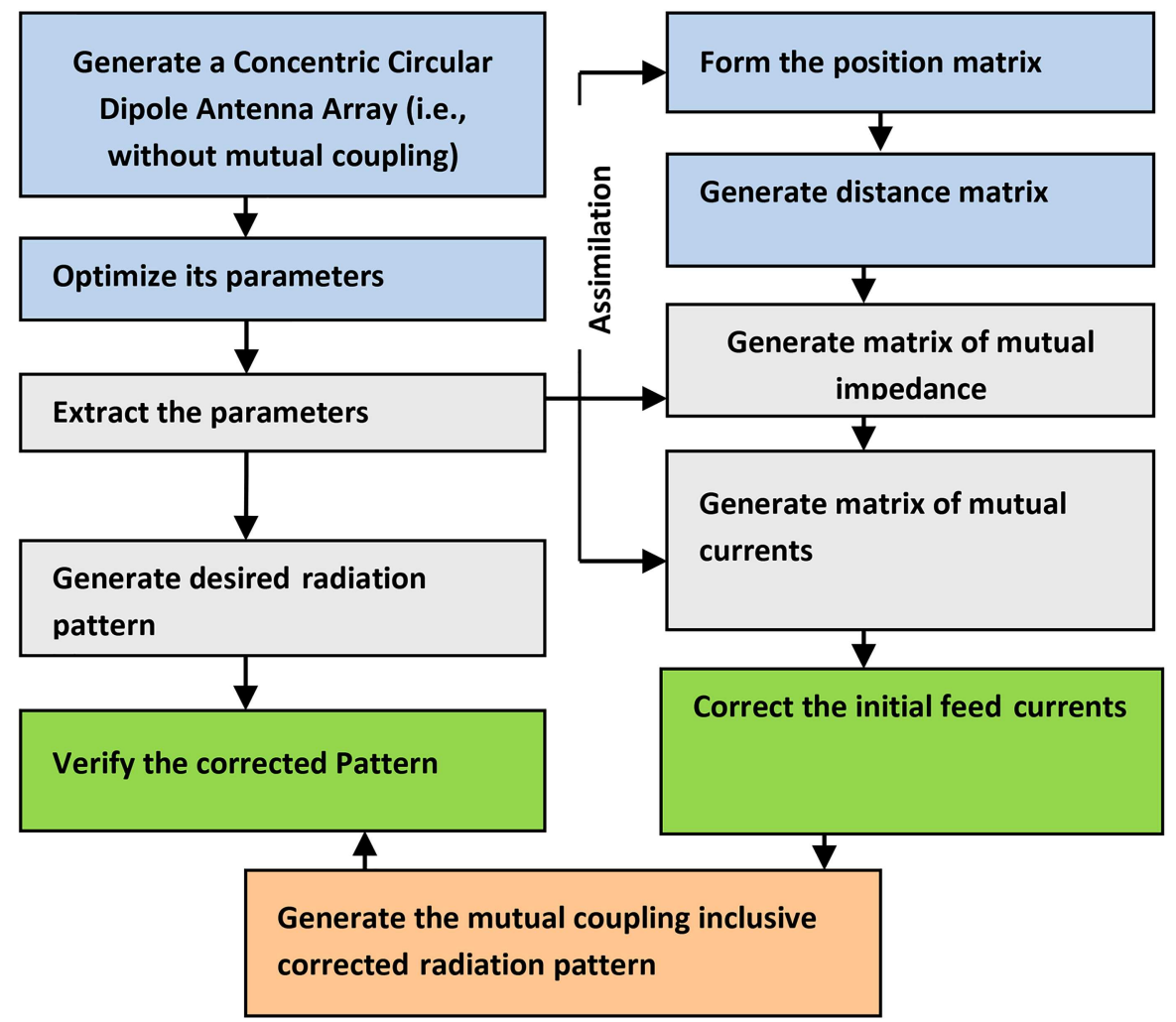

Figure 1. Flowchart of the parametric assimilation technique. 
mutual coupling effect and forms a set of final currents that causes a distorted radiation pattern. In the case of parametric assimilation technique, the distorted radiation pattern is forced to become equal to the desired pattern by replacing the final terminal currents with the currents of the desired radiation pattern.

\section{Design equation}

The geometrical configuration has an essential role in antenna array design. The circular antenna array is configured with $N$ number of non-uniformly spaced elements in the $\mathrm{x}-\mathrm{y}$ plane with a radius ' $a$ ' as shown in Figure 2, which scans a far-field point PP.

Given that all the elements of the Circular Antenna Array (CAA) are assumed isotropic, its far-field radiation pattern can be represented by its array factor $(A F)$ only.

From Figure 2, the array factor $A F(\theta, \phi, I)$ for the CAA may be written as Eq. (1):

$$
\begin{aligned}
A F(\theta, \phi, I)= & \sum_{n=1}^{N} I_{n} \exp (j \\
& {\left.\left[k a \sin \theta \cos \left(\phi-\phi_{n}\right)+\alpha_{n}\right]\right), }
\end{aligned}
$$

where:

$$
\begin{aligned}
& k a=\frac{2 \pi a}{\lambda}=\frac{\sum_{i=1}^{N} d_{i}}{\lambda}=N, \\
& \phi_{n}=2 \pi\left(\frac{n}{N}\right) .
\end{aligned}
$$

The current excitation weight of the $n$th element is denoted by $I_{n} ; k=2 \pi / \lambda$, where $\lambda$ is the wavelength of the plane wave; $d_{i}$ represents the inter-element spacing

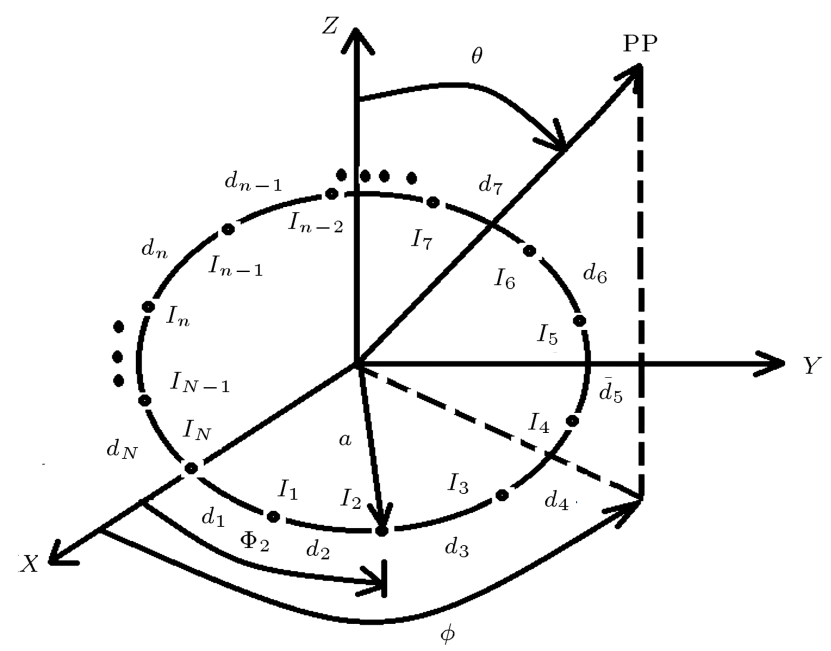

Figure 2. The geometry of N-element non-uniform circular antenna array laid on the $\mathrm{x}-\mathrm{y}$ plane for scanning at a point ' $\mathrm{PP}$ ' in the far-field. between the elements ' $i$ ' and ' $i+1$ '; $\theta$ symbolizes the elevation angle from the positive z-axis; and $\phi$ symbolizes the azimuth angle from the positive $\mathrm{x}$-axis; the angular position of the $n$th element along the $\mathrm{x}-\mathrm{y}$ plane is represented by $\phi_{n}$; the phase excitation weight of the $n$th element is given by $\alpha_{n}$; and the total number of elements in the CAA is represented by $N$.

The $A F$ value of Eq. (1) attains the maximum values when:

$$
k a \sin \theta \cos \left(\phi-\phi_{n}\right)+\alpha_{n}=2 m \pi,
$$

where:

$$
m=0, \pm 1, \pm 2, \ldots \pm n \text {. }
$$

The principal maximum $(m=0)$ is defined by the direction $\left(\theta_{0}, \phi_{0}\right)$ for which:

$$
\alpha_{n}=-k a \sin \theta_{0} \cos \left(\phi_{0}-\phi_{n}\right) ; \quad n=1,2, \ldots, N .
$$

For the present design, the peak of the main beam is directed in the $\left(\theta_{0}, \phi_{0}\right)$ direction; therefore, the following changes are to be assumed.

$$
\theta_{0}=\frac{\pi}{2}, \quad \alpha_{n}=-k a \cos \left(\phi_{0}-\phi_{n}\right) .
$$

Thus, Eq. (1) can be rewritten as follows:

$$
\begin{aligned}
A F(\theta, \phi, I)= & \sum_{n=1}^{N} I_{n} \exp \left(j k a \left[\cos \left(\phi-\phi_{n}\right)\right.\right. \\
& \left.\left.-\cos \left(\phi_{0}-\phi_{n}\right)\right]\right) .
\end{aligned}
$$

The parameter $\phi_{0}$ in Eq. (7) represents the direction of the main beam and the value is chosen as zero.

Now, all the isotropic elements of the CAA, as shown in Figure 2, are replaced with the dipole antennas to form the CDAA for practical consideration of mutual coupling effect and its correction by using parametric assimilation technique. The Far-Field Radiation Pattern (FFRP) of this CDAA is obtained by using pattern multiplication and is given in Eq. (8):

$$
F F R P(\theta, \phi, I)=A F(\theta, \phi, I) \times E P(\theta),
$$

where $\operatorname{EP}(\theta)$ is the element pattern of the dipole antenna and is given in Eq. (9):

$$
\operatorname{EP}(\theta)=\frac{\cos \left(\frac{\pi}{2} \cos \theta\right)}{\sin \theta},
$$

where $\theta$ is the angle between the axis of the dipole and the line of sight.

The directivity (DIR) has a vital role in the antenna array design. The directivity (DIR) is the ratio of the power density radiated from the array in a particular direction to the power density of an 
ideal isotropic element, which radiates uniformly in all directions. The directivity is calculated using Eq. (10):

$$
D I R=\frac{\left|F F R P_{0}\left(\theta_{0}, \phi_{0}\right)\right|^{2}}{\frac{1}{4 \pi} \int_{0}^{2 \pi} \int_{0}^{\pi}|F F R P(\theta, \phi)|^{2} \sin \theta d \theta d \phi} .
$$

The Cost Function (CF) formulation is another crucial part of the design of CDAA to obtain the optimal radiation pattern. The CF is given in Eq. (11):

$$
\begin{aligned}
C F= & W_{1} \times \frac{\left|F F R P\left(\theta_{m s 1}, I_{n i}\right)+F F R P\left(\theta_{m s 2}, I_{n i}\right)\right|}{\left|F F R P\left(\theta_{0}, I_{n i}\right)\right|} \\
& +W_{2} \times \frac{\left|\prod_{\theta=-\pi}^{\pi} F F R P\left(\theta_{S L L \_ \text {Peaks }}, I_{n i}\right)\right|}{\left|F F R P_{\max }\right|} \\
& +W_{3} \times\left[F N B W_{\text {Computed }}-F N B W\left(I_{n i}=1\right)\right] .
\end{aligned}
$$

The mutual coupling inclusive $\mathrm{CF}$ is given in Eq. (12), where the driving impedance of each element of the array is reduced by employing the optimal feed current excitation weights to obtain the mutual coupling inclusive far-field radiation pattern synthesis.

$$
\begin{aligned}
C F= & W_{1} \times \frac{\left|F F R P\left(\theta_{m s 1}, I_{n i}\right)+F F R P\left(\theta_{m s 2}, I_{n i}\right)\right|}{\left|F F R P\left(\theta_{0}, I_{n i}\right)\right|} \\
& +W_{2} \times \frac{\left|\prod_{\theta=-\pi}^{\pi} F F R P\left(\theta_{S L L \_P e a k s}, I_{n i}\right)\right|}{\left|F F R P_{\max }\right|} \\
& +W_{3} \times\left[F N B W_{\text {Computed }}-F N B W\left(I_{n i}=1\right)\right] \\
& +W_{4} \times\left(\frac{1}{Z_{D}}\right),
\end{aligned}
$$

where:

$$
Z_{D}=\sum_{n=1}^{N}\left(\frac{\sum_{i=1}^{N} I_{n i}}{I_{n i}}\right)
$$

Here, $W_{1}, W_{2}, W_{3}$, and $W_{4}$ represent the weighting factors of values $0.78,0.5,0.5$, and $0.43 ; \theta_{0}$ is the peak angle of $\theta$ in the main beam; $\theta_{m s 1}$ and $\theta_{m s 2}$ represent the angles of the maximum sidelobe below and above the peak angle of the main beam, respectively; the $n i$ th element's current excitation weight is represented by $I_{n i}$. The angular distance between the first two nulls on both sides of the main beam is called FNBW. Thus, FNBW $W_{\text {Computed }}$ refers to the optimized FNBW value obtained using non-uniform current excitation, whereas $F N B W\left(I_{n i}=1\right)$ represents the FNBW value obtained by using uniform excitation to all the array elements. The third term of the $\mathrm{CF}$ is considered only if $F N B W_{\text {Computed }}>F N B W\left(I_{n i}=1\right)$ and it is applied for the narrowing of FNBW to improve the directivity of the radiation pattern.

The second term of the CF is included here to suppress the SLL value by imposing nulls on all the peaks of side lobes of the radiation pattern. The peak values of SLL are represented by $F F R P\left(\theta_{S L L \_}\right.$Peaks,$\left.I_{n i}\right)$ within $\theta \in\left[-\pi: \theta_{m s 1}, \theta_{m s 2:}: \pi\right] ;\left|F F R P_{\max }\right|$ is the maximum value of FFRP. The product term of all the FFRP $\left(\theta_{S L L \_P e a k s}, I_{n i}\right)$ values is represented by $\prod_{\theta=-\pi}^{\pi}$. Hence, the CF minimization signifies the maximum reduction of SLL as well as FNBW value. Much research has already been done for the optimal radiation pattern synthesis of CAA using different optimization techniques [18-34]. However, in this paper, GWO algorithm is employed to optimize the current excitation weights and inter-element spacing among the array elements of the CDAA to achieve the maximum reduction of $\mathrm{CF}$ value.

\section{Grey Wolf Optimization (GWO)}

Grey Wolf Optimization (GWO) is a stochastic algorithm that can be employed for dealing with different optimization problems without any significant change in the structure of the algorithm. The GWO [23,24] algorithm begins with a random solution which does not depend on the calculation of the derivative of search spaces; therefore, it is highly suitable for real problems with unknown derivative information. GWO is a robust meta-heuristic optimization technique adopted here to determine the optimal solution of the CDAA design problem. Grey wolves live in a group and follow a social hierarchical structure where the alpha wolves are positioned at the top most level. All other members of the pack follow the decisions of alpha wolves. The position of beta wolves is after the alpha wolves in the hierarchy. Beta wolves take part in decision-making with the alpha wolves, reinforce the decision of alpha wolves to the pack, and provide the feedback at its upper level. The omega wolves belong to the lowermost level in the hierarchy, whereas the position of delta wolves is in the middle so as to dominate the omega wolves but submit to alpha and beta wolves. The social hierarchical structure of grey wolves is shown in Figure 3.

The synthesis of CDAA by employing GWO algorithm is presented as a flowchart in Figure 4. The following four steps mathematically model the GWO algorithm:

I. Social hierarchy. The hierarchy of grey wolves 


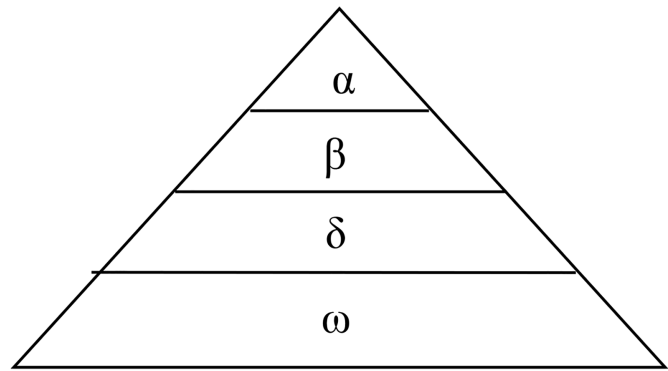

Figure 3. Hierarchy of grey wolves.

shows that the best solutions are presented by alpha $(\alpha)$, beta $(\beta)$, and delta $(\delta)$. The remaining solution is omega $(\omega)$.

II. Encircling the Prey. The encircling behavior is presented as follows:

$$
\begin{aligned}
& \vec{D}=\left|\vec{C} \cdot \vec{X}_{p}(t)-\vec{X}(t)\right|, \\
& \vec{X}(t+1)=\vec{X}_{p}(t)-\vec{A} \cdot(\vec{D}),
\end{aligned}
$$

where $t$ denotes the present iteration; $\vec{A}$ and $\vec{C}$ are the coefficients vectors; the position vectors of the prey and the grey wolf are denoted by $\vec{X}_{p}$ and $\vec{X}$, respectively. The values of $\vec{A}$ and $\vec{C}$ are given in Eq. (16):

$$
\left.\begin{array}{l}
\vec{A}=2 \vec{a} \cdot \vec{r}_{1}-\vec{a} \\
\vec{C}=2 \cdot \vec{r}_{2}
\end{array}\right\}
$$

$\vec{a}$ decreases continuously from 2 to 0 with the number of iterations; $\vec{r}_{1}$, and $\vec{r}_{2}$ are the random vectors in the range of $[0,1]$.

III. Hunting. In GWO, the hunting is followed as a hierarchical structure by alpha $(\alpha)$, beta $(\beta)$, and delta $(\delta)$. The omega $(\omega)$ wolves follow $\alpha, \beta$, and $\delta$ wolves. Hence, $\alpha, \beta$, and $\delta$ estimate the position of the prey and the remaining wolves take their positions randomly around the prey.

IV. Attacking prey (exploitation). The pack of grey wolves attack the prey when the prey stops moving. This exploitation mechanism of GWO algorithm is mathematically represented by decreasing

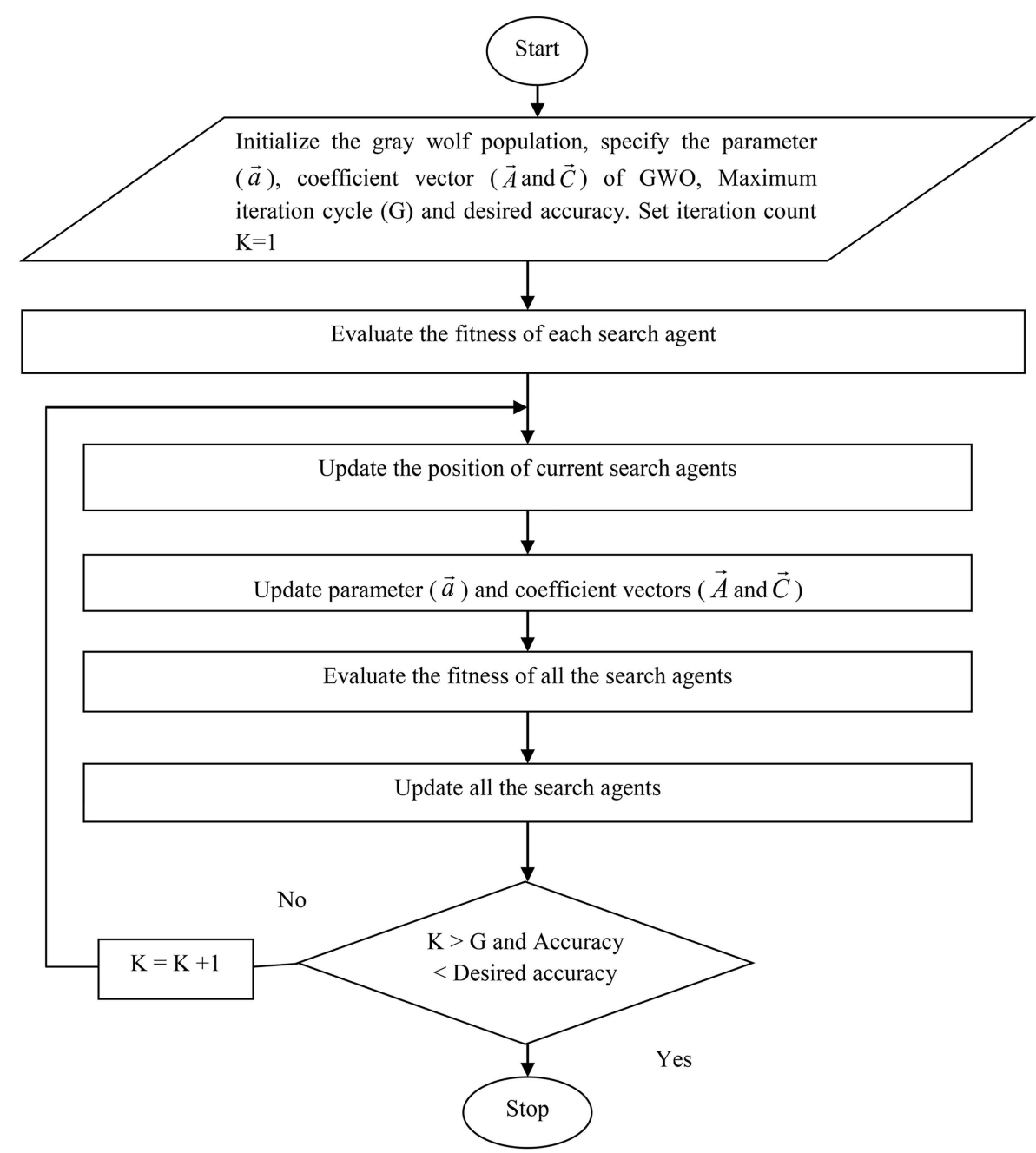

Figure 4. Flowchart for GWO algorithm. 
the value of $\vec{a}$ which in turn decreases the value of $\vec{A}$. The value of $\vec{a}$ decreases from 2 to 0 with the iteration cycle. Now, when $|\vec{A}|<1$, the wolves are forced to attack the prey.

V. Searching prey (exploration). In GWO, the grey wolves diverge from each other to search for prey and converge to attack prey. The values of $|\vec{A}|>1$ and $|\vec{A}|<1$ imply that the grey wolves should diverge from and converge to the prey, respectively. Another critical parameter in GWO is $\vec{C}$ that controls the exploration, and local optimum avoidance by controlling stochastical emphasizes $(\vec{C}>1)$ or deemphasizes $(\vec{C}<1)$ and terminates by satisfying the end criterion.

The meta-heuristic techniques can be broadly classified into two categories, known as single solution-based and population-based. Single solution-based algorithm suffers due to the premature convergence, which averts the algorithm to find the global best solution. However, the population-based meta-heuristic algorithms, like GWO, enjoy sharing the information about the search space with multiple candidate solutions so as to help the candidate solution to jump toward the most promising part of the search space. Another advantage of GWO algorithm is that it can avoid local optima by employing multiple candidate solutions, which assist each other.

The reputation of the GWO algorithm comes from the following reasons:

i. The hierarchical structure of grey wolves pack helps them to remember the best solution achieved throughout the iterations.

ii. The method of encircling the prey in GWO algorithm shows a circular neighborhood around the solution and can be expanded to a higher dimension as a hyper-sphere.

iii. The parameters $\vec{A}$ and $\vec{C}$ in GWO algorithm help the candidate solution have different random radii in the hyper-sphere.

iv. The hunting mechanism in GWO algorithm helps the candidate solution to determine the probable position of the prey.

v. The method of exploration and exploitation is balanced by the adaptive parameter values of $\vec{a}$ and $\vec{A}$.

vi. The prime advantage of GWO algorithm is that only two main parameters $(\vec{a}$ and $\vec{C})$ must be adjusted.

Therefore, GWO can be considered as an openended algorithm for solving various optimization problems.

\section{Results and discussions}

PSO, DE, and GWO algorithms are applied here to obtain the optimal current excitation amplitude weights and inter-element spacing for the CDAA design. The best results are obtained through 50 trial runs for each algorithm with their best control parameters using MATLAB 7.5 version in Intel Core (TM) 2 duo processor, $3.00 \mathrm{GHz}$ with $3 \mathrm{~GB}$ RAM. The best control parameters of different algorithms are shown in Table 1.

\subsection{Simulation results of Circular Dipole Antenna Array (CDAA)}

This section shows the comparison among the desired radiation patterns (Case-I), the uncorrected radiation patterns (Case-II), and the corrected radiation patterns (Case-III) achieved by using parametric assimilation technique. The values of current excitation weights and inter-element spacing obtained from the desired patterns are taken into account without considering the mutual coupling effect for 8- and 10-element CDAA designs by using GWO, DE, and PSO optimization techniques and are shown here as Case-I. The uncorrected radiation patterns are obtained using different optimization techniques for CDAA synthesis considering the mutual coupling effect and are shown here as Case-II. Case-III shows the corrected radiation patterns considering the mutual coupling effect obtained through parametric assimilation technique for 8- and 10-element CDAA designs using different optimization techniques.

The optimal current excitation weights and interelement spacing for 8-element CDAA obtained from the GWO algorithm are shown in Table 2 and are plotted in Figure 5.

Table 3 shows the optimal current excitation

Table 1. Control parameters using different algorithms.

\begin{tabular}{cccc}
\hline Parameters & PSO & DE & GWO \\
\hline Population size & 100 & 100 & 100 \\
Iteration cycle & 500 & 500 & 500 \\
$\vec{a}$ & - & - & $2-0$ \\
$\vec{r}_{1}$ & - & - & $(0,1)$ \\
$\vec{r}_{2}$ & - & - & $(0,1)$ \\
$\vec{A}$ & - & - & $(-1,1)$ \\
$\vec{C}$ & - & - & $(0,2)$ \\
$C_{1}, C_{2}$ & $1.5,1.5$ & - & - \\
$\nu_{\min }^{i}, \nu_{\max }^{i}$ & $0.01,1.0$ & - & - \\
$W_{\max }, W_{\min }$ & $1.0,0.4$ & - & - \\
$C_{r}$ & - & 0.3 & - \\
$\mathrm{F}$ & - & 0.5 & - \\
\hline
\end{tabular}


Table 2. Optimal current excitation amplitude weights and inter-element spacing of CDAA by using GWO algorithm.

\begin{tabular}{|c|c|c|c|c|c|c|c|c|c|}
\hline \multirow[t]{2}{*}{$\begin{array}{l}\text { No. of } \\
\text { elements }\end{array}$} & \multirow{2}{*}{$\begin{array}{c}\begin{array}{c}\text { Pattern } \\
\text { type }\end{array} \\
\text { Case-I }\end{array}$} & \multicolumn{4}{|c|}{$\begin{array}{c}\text { Current excitation } \\
\text { weights }\end{array}$} & \multicolumn{3}{|c|}{$\begin{array}{c}\text { Inter-element spacing } \\
(\lambda)\end{array}$} & \multirow{2}{*}{$\begin{array}{c}\text { Radius of the array } \\
(\boldsymbol{\lambda}) \\
\\
0.9230\end{array}$} \\
\hline & & $\begin{array}{l}0.2601 \\
0.3210 \\
0.2624\end{array}$ & $\begin{array}{r}0.0010 \\
0.3343 \\
0.1941\end{array}$ & $\begin{array}{l}0.1464 \\
0.1460\end{array}$ & & $\begin{array}{ll}0.3608 & 0.5837 \\
0.5434 & 0.9025\end{array}$ & $\begin{array}{r}0.7790 \\
1.3864\end{array}$ & $\begin{array}{l}0.9013 \\
0.3426\end{array}$ & \\
\hline \multirow[t]{3}{*}{8} & Case-II & $\begin{array}{l}0.8251 \\
0.9964 \\
0.4228\end{array}$ & $\begin{array}{c}0.7018 \\
0.4933 \\
0.1669\end{array}$ & $\begin{array}{l}0.9962 \\
0.5697\end{array}$ & & $\begin{array}{ll}0.3377 & 0.8274 \\
0.6306 & 0.8538 \\
0.2499 & 0.1895\end{array}$ & $\begin{array}{r}0.8575 \\
0.7092\end{array}$ & & 0.7409 \\
\hline & Case-III & $\begin{array}{l}0.6810 \\
0.9770 \\
0.7100 \\
\end{array}$ & $\begin{array}{c}0.3621 \\
0.3364 \\
0.2548 \\
\end{array}$ & $\begin{array}{r}0.9428 \\
0.0026\end{array}$ & & $\begin{array}{lc}0.3392 & 0.7676 \\
0.6080 & 0.8459 \\
0.4615 & 0.3263 \\
\end{array}$ & $\begin{array}{r}0.8498 \\
0.3283\end{array}$ & & 0.7204 \\
\hline & Case-I & $\begin{array}{l}0.3193 \\
0.5039 \\
0.2670 \\
0.4785\end{array}$ & $\begin{array}{c}0.3452 \\
0.4943 \\
0.0449\end{array}$ & $\begin{array}{c}0.2065 \\
0.1454 \\
0.3286\end{array}$ & & $\begin{array}{ll}0.6804 & 1.0275 \\
0.5525 & 1.1356 \\
0.8502 & 0.6077\end{array}$ & $\begin{array}{l}1.8985 \\
1.5078\end{array}$ & $\begin{array}{l}1.5756 \\
0.8023\end{array}$ & 1.6931 \\
\hline \multirow[t]{2}{*}{10} & Case-II & $\begin{array}{l}0.1304 \\
0.0309 \\
0.0606 \\
0.1488\end{array}$ & $\begin{array}{c}0.1051 \\
0.1421 \\
0.1167\end{array}$ & $\begin{array}{l}0 \\
0.1405 \\
0.0862\end{array}$ & & $\begin{array}{cc}0.5772 & 1.0382 \\
0.5705 & 0.5733 \\
0.9970 & 0.6201\end{array}$ & $\begin{array}{r}1.0242 \\
1.1843\end{array}$ & $\begin{array}{c}1.0967 \\
1.4350\end{array}$ & 1.4509 \\
\hline & Case-III & $\begin{array}{l}0.6563 \\
0.8310 \\
0.3901\end{array}$ & $\begin{array}{c}0.6619 \\
0.3194 \\
1.0000\end{array}$ & $\begin{array}{c}0.4060 \\
0.2825\end{array}$ & $\begin{array}{l}0.8677 \\
0.6239\end{array}$ & $\begin{array}{lc}0.5978 & 1.6566 \\
0.5644 & 1.5044 \\
1.0771 & 0.6208\end{array}$ & $\begin{array}{l}0.8421 \\
0.7707\end{array}$ & $\begin{array}{l}1.7976 \\
1.2166\end{array}$ & 1.6946 \\
\hline
\end{tabular}

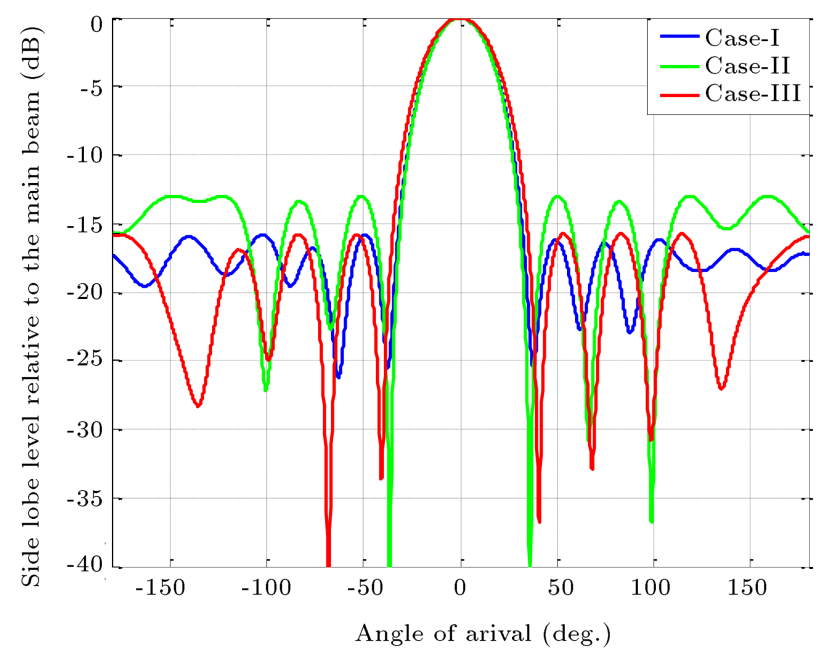

Figure 5. Radiation patterns of 8-element CDAA using GWO.

weights and inter-element spacing of CDAA obtained by using DE optimization technique for 8-element CDAA synthesis for Case-I, Case-II, and Case-III and are plotted in Figure 6. The PSO optimization-based results for Case-I, Case-II, and Case-III of 8-element CDAA synthesis are shown in Table 4 and are plotted in Figure 7.

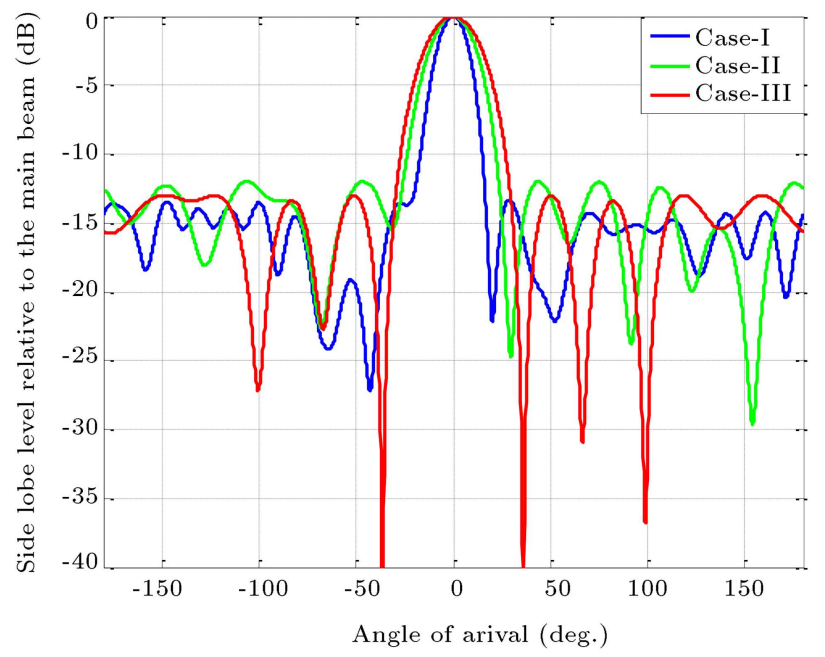

Figure 6. Radiation patterns of 8-element CDAA using DE.

The optimal current excitation weights and interelement spacing for 10-element CDAA obtained from using GWO algorithm are shown in Table 2 and are plotted in Figure 8.

Table 3 shows the optimal current excitation weights and inter-element spacing of CDAA obtained by using DE optimization technique for 10-element 
Table 3. Optimal current excitation amplitude weights and inter-element spacing of CDAA by using DE algorithm.

\begin{tabular}{|c|c|c|c|c|c|c|c|c|c|}
\hline \multirow[t]{2}{*}{$\begin{array}{l}\text { No. of } \\
\text { elements }\end{array}$} & \multirow[t]{2}{*}{$\begin{array}{c}\text { Pattern } \\
\text { type }\end{array}$} & \multicolumn{4}{|c|}{$\begin{array}{c}\text { Current excitation } \\
\text { weights }\end{array}$} & \multicolumn{3}{|c|}{$\begin{array}{c}\text { Inter-element spacing } \\
(\lambda)\end{array}$} & \multirow[t]{2}{*}{$\begin{array}{c}\text { Radius of the array } \\
(\lambda)\end{array}$} \\
\hline & & 0.3660 & 0.3661 & 0.5332 & & 1.6299 & 1.3561 & 1.2329 & \\
\hline \multirow{8}{*}{8} & Case-I & 0.5958 & 0.1739 & 0.3372 & & 0.5738 & 1.1707 & 1.5322 & 1.4439 \\
\hline & & 0.5699 & 0.5229 & & & 1.0061 & 0.5708 & & \\
\hline & & 0.3047 & 0.4840 & 0.7751 & & 0.9997 & 0.7743 & 0.9042 & \\
\hline & Case-II & 0.9867 & 0.3371 & 0.4422 & & 0.5652 & 0.8056 & 0.7818 & 0.9350 \\
\hline & & 0.4067 & 0.6807 & & & 0.5848 & 0.4594 & & \\
\hline & & 0.8251 & 0.7018 & 0.9962 & & 0.3377 & 0.8274 & 0.8575 & \\
\hline & Case-III & 0.9964 & 0.4933 & 0.5697 & & 0.6306 & 0.8538 & 0.7092 & 0.7409 \\
\hline & & 0.4228 & 0.1669 & & & 0.2499 & 0.1895 & & \\
\hline \multirow{12}{*}{10} & & 0.1304 & 0.1051 & 0 & & 0.5772 & 1.0382 & 1.0242 & \\
\hline & Casse-I & 0.0309 & 0.1421 & 0.1405 & & 1.0967 & 0.5705 & 0.5733 & 14509 \\
\hline & & 0.0606 & 0.1167 & 0.0862 & & 1.1843 & 1.4350 & 0.9970 & \\
\hline & & 0.1488 & & & & 0.6201 & & & \\
\hline & & 0.6920 & 0.5679 & 0.5937 & 0.6703 & 0.6221 & 0.9880 & 0.7777 & \\
\hline & Case-II & 0.9693 & 0.6014 & 03575 & & 0.9934 & 0.6217 & 0.9514 & 1.2766 \\
\hline & & & & & & 0.7626 & 0.5980 & 0.7655 & \\
\hline & & & & & & 0.9410 & & & \\
\hline & & & & & & 0.5301 & 1.0603 & 1.3264 & \\
\hline & Case-III & 0.8970 & 1.0000 & 0.7679 & 0.8899 & 1.0000 & 0.4307 & 0.4408 & 1.4692 \\
\hline & & & 10000 & & & 1.5276 & 1.3255 & 1.0000 & \\
\hline & & & & & & 0.5904 & & & \\
\hline
\end{tabular}

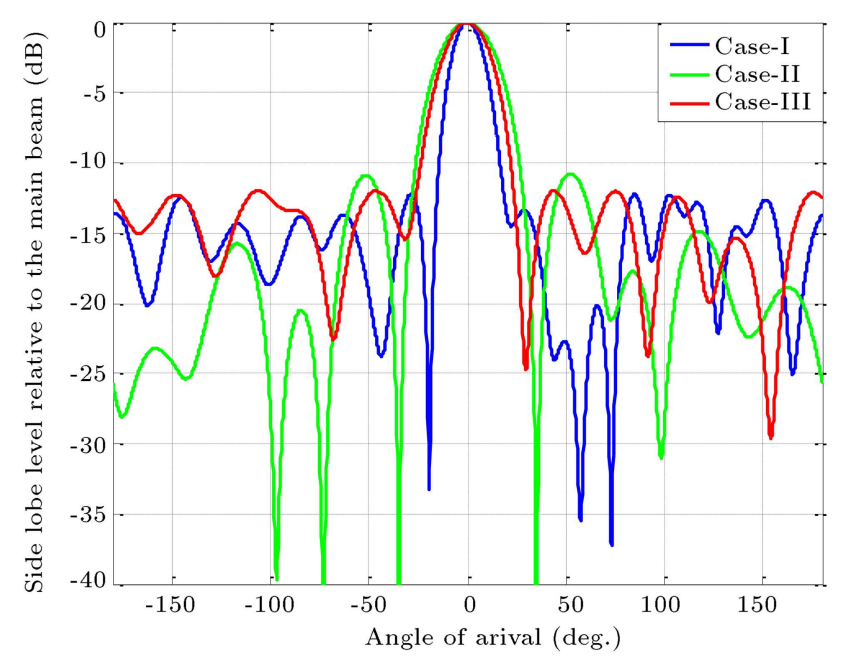

Figure 7. Radiation patterns of 8-element CDAA using PSO.

CDAA synthesis for Case-I, Case-II, and Case-III and are plotted in Figure 9.

The PSO optimization-based results for Case-I, Case-II, and Case-III of 10-element CDAA synthesis are shown in Table 4 and are plotted in Figure 10.

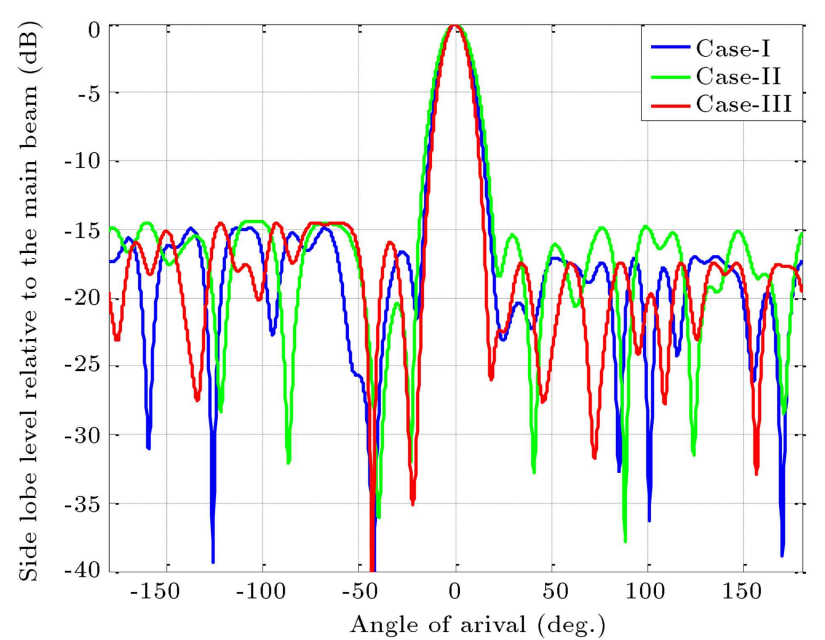

Figure 8. Radiation patterns of 10-element CDAA using GWO.

The radiation pattern plots shown in Figures 5 to 10 using different algorithms for 8- and 10element CDAA designs depict a significant distortion in the uncorrected pattern as plotted here in Case-II, which is forced to become equal to the desired pattern 
Table 4. Optimal current excitation amplitude weights and inter-element spacing of CDAA by using PSO algorithm.

\begin{tabular}{|c|c|c|c|c|c|c|c|c|}
\hline $\begin{array}{c}\text { No. of } \\
\text { elements }\end{array}$ & $\begin{array}{l}\text { Pattern } \\
\text { type }\end{array}$ & Curr & $\begin{array}{l}\text { ext exci } \\
\text { weights }\end{array}$ & tation & Inter-e & $\begin{array}{l}\text { lement } \\
\qquad(\lambda)\end{array}$ & spacing & $\begin{array}{c}\text { Radius of the } \\
\operatorname{array}(\lambda)\end{array}$ \\
\hline \multirow{9}{*}{8} & \multirow{3}{*}{ Case-I } & 1.0000 & 0.6736 & 0.1678 & 0.6341 & 1.0000 & 1.8892 & \multirow{3}{*}{1.4438} \\
\hline & & 1.0000 & 0.9088 & 0.6553 & 0.8456 & 0.5693 & 1.1639 & \\
\hline & & 0.7571 & 1.0000 & & 1.3329 & 1.6367 & & \\
\hline & \multirow{3}{*}{ Case-II } & 0.7765 & 0.3928 & 0.6069 & 0.3590 & 0.5756 & 0.2494 & \multirow{3}{*}{0.7150} \\
\hline & & 0.8446 & 1.0000 & 0.7015 & 0.7638 & 0.6025 & 0.8311 & \\
\hline & & 0.9321 & 0.3583 & & 0.7809 & 0.3308 & & \\
\hline & \multirow{3}{*}{ Case-III } & 0.3047 & 0.4840 & 0.7751 & 0.9997 & 0.7743 & 0.9042 & \multirow{3}{*}{0.9350} \\
\hline & & 0.9867 & 0.3371 & 0.4422 & 0.5652 & 0.8056 & 0.7818 & \\
\hline & & 0.4067 & 0.6807 & & 0.5848 & 0.4594 & & \\
\hline \multirow{12}{*}{10} & \multirow{4}{*}{ Case-I } & 1.0000 & 1.0000 & 1.0000 & 0.5301 & 1.0603 & 1.3264 & \multirow{4}{*}{1.4692} \\
\hline & & 0.3819 & 0.8970 & 1.0000 & 1.0000 & 0.4307 & 0.4408 & \\
\hline & & 0.7679 & 0.8899 & 0.7246 & 1.5276 & 1.3255 & 1.0000 & \\
\hline & & 1.0000 & & & 0.5904 & & & \\
\hline & \multirow{4}{*}{ Case-II } & 1.0000 & 0.7529 & 0.7519 & 0.3170 & 0.9654 & 0.3859 & \multirow{4}{*}{0.9394} \\
\hline & & 1.0000 & 0.5062 & 1.0000 & 0.9654 & 0.3185 & 0.3164 & \\
\hline & & 0.7501 & 0.7524 & 1.0000 & 0.9657 & 0.3862 & 0.9650 & \\
\hline & & 0.5067 & & & 0.3174 & & & \\
\hline & \multirow{4}{*}{ Case-III } & 0.7081 & 0.2682 & 0.3713 & 0.3810 & 0.7453 & 0.2668 & \multirow{4}{*}{0.9660} \\
\hline & & 0.4100 & 0.8800 & 0.9665 & 0.3142 & 1.0000 & 0.6032 & \\
\hline & & 0.4165 & 0.5813 & 0.7494 & 0.9706 & 0.5713 & 0.8800 & \\
\hline & & 0.5403 & & & 0.3376 & & & \\
\hline
\end{tabular}

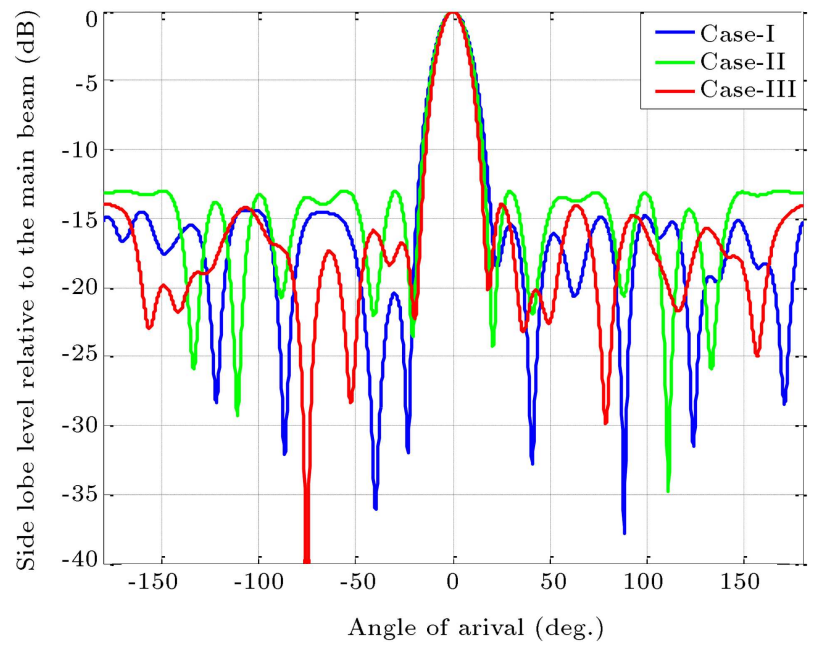

Figure 9. Radiation patterns of 10-element CDAA using DE.

(Case-I) by using parametric assimilation technique to achieve the corrected radiation pattern (Case-III). The parametric assimilation technique, with the help of the GWO algorithm, could correct the erred radiation pattern nearly equal to the desired pattern for 8-

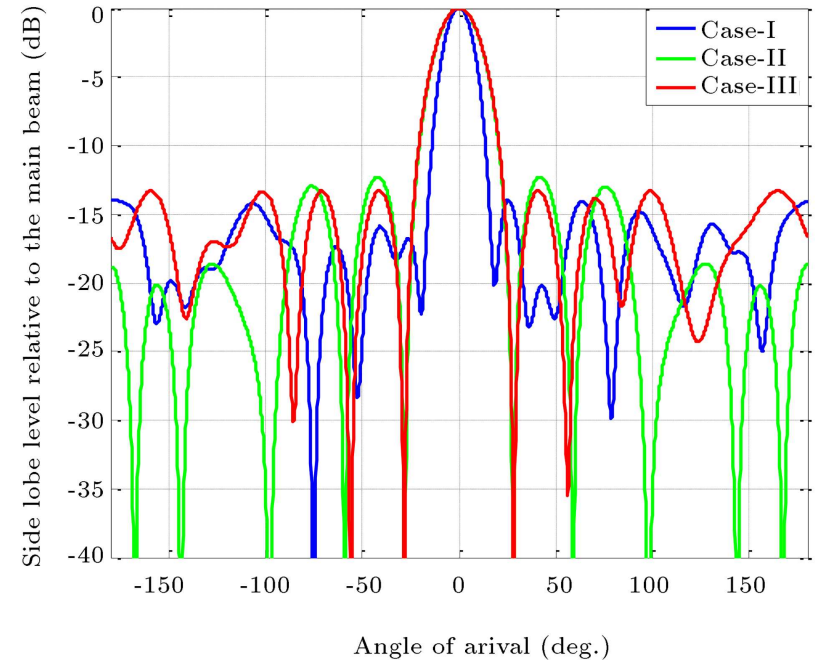

Figure 10. Radiation patterns of 10-element CDAA using PSO.

and 10-element CDAA synthesis. In all the plots of radiation pattern for all the cases of 8- to 10-element CDAA designs, the PSO, DE, and GWO algorithmbased results are compared. All the plots of radiation 
Table 5. Different parameters of CDAAs radiation pattern characteristic obtained by using different algorithms.

\begin{tabular}{|c|c|c|c|c|c|}
\hline No. of Elements & Algorithm & Pattern type & SLL (dB) & FNBW (deg.) & Directivity (dBi) \\
\hline \multirow{9}{*}{8} & \multirow{3}{*}{ GWO } & Case-I & -15.80 & 75.60 & 8.7662 \\
\hline & & Case-II & -13.00 & 72.36 & 8.7734 \\
\hline & & Case-III & -15.80 & 81.36 & 8.9311 \\
\hline & \multirow{3}{*}{$\mathrm{DE}$} & Case-I & -13.33 & 42.12 & 8.2303 \\
\hline & & Case-II & -12.00 & 59.94 & 8.4236 \\
\hline & & Case-III & -13.00 & 71.64 & 9.0734 \\
\hline & \multirow{3}{*}{ PSO } & Case-I & -12.25 & 41.22 & 9.7312 \\
\hline & & Case-II & -10.92 & 69.12 & 9.2583 \\
\hline & & Case-III & -12.04 & 60.30 & 8.4236 \\
\hline \multirow{9}{*}{10} & \multirow{3}{*}{ GWO } & Case-I & -14.93 & 44.46 & 9.7863 \\
\hline & & Case-II & -14.51 & 45.90 & 9.1518 \\
\hline & & Case-III & -14.56 & 40.68 & 9.8058 \\
\hline & \multirow{3}{*}{$\mathrm{DE}$} & Case-I & -14.51 & 45.54 & 9.1518 \\
\hline & & Case-II & -13.27 & 41.04 & 9.5640 \\
\hline & & Case-III & -13.97 & 37.98 & 9.9306 \\
\hline & \multirow{3}{*}{$\mathrm{PSO}$} & Case-I & -14.00 & 37.98 & 9.9306 \\
\hline & & Case-II & -12.34 & 55.44 & 10.5066 \\
\hline & & Case-III & -13.32 & 56.70 & 9.3795 \\
\hline
\end{tabular}

pattern confirm the superior optimizing capability of GWO over PSO and DE.

Table 5 shows the SLL, FNBW, and directivity values obtained by different algorithms for Case-I, Case-II, and Case-III types of 8- and 10-element CDAA designs. The results of Table 5 show that the SLL and FNBW values for the desired pattern and the corrected pattern for both of the arrays are almost equal, whereas the values for the uncorrected pattern differ significantly from the desired and corrected patterns by using different algorithms for 8- and 10-element CDAA designs. Hence, the results show that the parametric assimilation technique performs suitably for mutual coupling affected erred radiation pattern correction nearly equal to the form of the desired radiation pattern. The results of Table 5 show that GWO algorithm-based results outperform the PSO and DE algorithm-based results.

\subsection{Statistical results of Circular Dipole Antenna Array (CDAA)}

Statistical parameters of the $\mathrm{CF}$ and the execution time for 8- and 10-element CDAA designs of Case-I, Case-II, and Case-III types of radiation pattern synthesis using different algorithms are shown in Table 6 . The results in Table 6 offer a strong justification for the robustness and stability of the GWO algorithm-based design.

Table 7 shows the results of the statistical tests achieved using independent samples to compare whether the GWO algorithm-based results differ significantly from the PSO and DE algorithm-based results. Here, two-sample t-test [35] is conducted in the case of GWO/PSO and GWO/DE algorithms to prove the difference between the two algorithms based on statistical analysis.

The authors achieved t-test values larger than 2.15, at the degree of freedom 49, signifying the difference between GWO/PSO and GWO/DE algorithms with a $98 \%$ confidence level. Thus, the results of statistical tests represent strong evidence for the efficiency and robustness of the GWO algorithm.

\subsection{Deviation of current amplitude excitation analysis for the synthesis of the circular dipole antenna array}

The current amplitude excitation weights achieved by employing different optimization techniques for the synthesis of 8-element and 10-element CDAAs are not actual values; rather, normalized current amplitude excitation weights are employed here for the synthesis of 
Table 6. Statistical parameters of CF obtained by using different algorithms.

\begin{tabular}{|c|c|c|c|c|c|c|c|}
\hline $\begin{array}{c}\text { No. of } \\
\text { elements }\end{array}$ & Algorithm & $\begin{array}{c}\text { Pattern } \\
\text { type }\end{array}$ & $\begin{array}{c}\text { Minimum } \\
\text { CF }\end{array}$ & $\begin{array}{c}\text { Maximum } \\
\text { CF }\end{array}$ & $\begin{array}{c}\text { Mean } \\
\text { CF }\end{array}$ & $\begin{array}{l}\text { Standard } \\
\text { deviation }\end{array}$ & $\begin{array}{l}\text { Execution } \\
\text { time (min) }\end{array}$ \\
\hline \multirow{6}{*}{8} & \multirow{3}{*}{ GWO } & Case-I & 0.3361 & 0.7103 & 0.6155 & 0.1159 & 4.0111 \\
\hline & & Case-II & 0.3984 & 0.7638 & 0.6796 & 0.0994 & 4.5751 \\
\hline & & Case-III & 0.3509 & 0.7549 & 0.6187 & 0.1293 & 4.7124 \\
\hline & \multirow{3}{*}{$\mathrm{DE}$} & Case-I & 0.5142 & 0.8704 & 0.7855 & 0.1183 & 3.6121 \\
\hline & & Case-II & 0.6311 & 0.9867 & 0.8923 & 0.0967 & 4.9747 \\
\hline & & Case-III & 0.5634 & 0.9533 & 0.8140 & 0.1170 & 5.0117 \\
\hline & \multirow{3}{*}{ PSO } & Case-I & 0.6984 & 0.9636 & 0.8905 & 0.0876 & 3.5712 \\
\hline & & Case-II & 0.7725 & 1.1366 & 1.0179 & 0.1040 & 4.8121 \\
\hline & & Case-III & 0.7393 & 1.1519 & 0.9915 & 0.1373 & 5.4907 \\
\hline \multirow{9}{*}{10} & \multirow{3}{*}{ GWO } & Case-I & 0.4542 & 0.8674 & 0.7956 & 0.1210 & 3.7124 \\
\hline & & Case-II & 0.5322 & 0.9278 & 0.8173 & 0.1287 & 3.9717 \\
\hline & & Case-III & 0.4855 & 0.8801 & 0.7914 & 0.0943 & 5.6619 \\
\hline & \multirow{3}{*}{$\mathrm{DE}$} & Case-I & 0.6178 & 1.3253 & 0.9948 & 0.2407 & 3.7191 \\
\hline & & Case-II & 0.6795 & 1.0521 & 0.9789 & 0.1076 & 4.7987 \\
\hline & & Case-III & 0.6441 & 1.0312 & 0.9166 & 0.1292 & 5.9176 \\
\hline & \multirow{3}{*}{$\mathrm{PSO}$} & Case-I & 0.7140 & 1.0791 & 0.9768 & 0.1282 & 4.7587 \\
\hline & & Case-II & 0.8219 & 1.2115 & 1.1062 & 0.1080 & 4.8777 \\
\hline & & Case-III & 0.7730 & 1.1518 & 0.9950 & 0.1075 & 5.8331 \\
\hline
\end{tabular}

Table 7. Comparative t-test values.

\begin{tabular}{cccc}
\hline $\begin{array}{c}\text { No. of } \\
\text { elements }\end{array}$ & Pattern type Algorithm t-test value \\
\hline \multirow{4}{*}{8} & Case-I & GWO/PSO & 13.3847 \\
& & GWO/DE & 8.1662 \\
& Case-II & GWO/PSO & 16.6280 \\
& & GWO/DE & 10.8455 \\
& Case-III & GWO/PSO & 13.9772 \\
& & GWO/DE & 7.9195 \\
\hline \multirow{3}{*}{10} & Case-I & GWO/PSO & 7.2682 \\
& & GWO/DE & 5.2285 \\
& Case-II & GWO/PSO & 12.1589 \\
& & GWO/DE & 6.8117 \\
& Case-III & GWO/PSO & 10.0677 \\
& & GWO/DE & 5.5347 \\
\hline
\end{tabular}

far-field radiation patterns of 8-element and 10-element CDAAs and can be easily implemented by using Radio Frequency (RF) oscillators. The deviations of current amplitude excitation analysis are given in Tables 8 and 9 to explore the effect of current amplitude deviation on the far-field radiation pattern.

Table 8 shows the optimal radiation pattern achieved by using the optimal current amplitude excitation weights and inter-element spacing by employing GWO algorithm for 8- and 10-element CDAA synthesis for different cases (Case-I, Case-II, and Case-III) and the deviated radiation pattern obtained by changing only the current amplitude excitation weights of the optimal radiation pattern in the second decimal point with the increment of 0.0500 , keeping the inter-element spacing unaltered as given in the optimal radiation pattern.

Figures 11 and 12 plot the different cases (CaseI, Case-II, and Case-III) of the radiation pattern for the results as given in Table 8 to explore the effect of the deviation of the current amplitude excitation weights for the synthesis of 8- and 10-element CDAAs by employing the GWO algorithm. The results show significant changes in maximum SLL by increasing the current amplitude excitation weights in the second decimal points.

Table 9 shows the analytical results of the deviation of current amplitude excitation weights achieved by employing the GWO algorithm for different cases (Case-I, Case-II, and Case-III) of 8- and 10-element CDAA synthesis. The table contains the deviated radiation pattern obtained by changing the current amplitude excitation weights at the second decimal 
Table 8. Deviation of current amplitude excitation weights analysis with the fixed inter-element spacing obtained by using GWO algorithm for the synthesis of CDAA by increasing the current amplitude excitation in the second decimal.

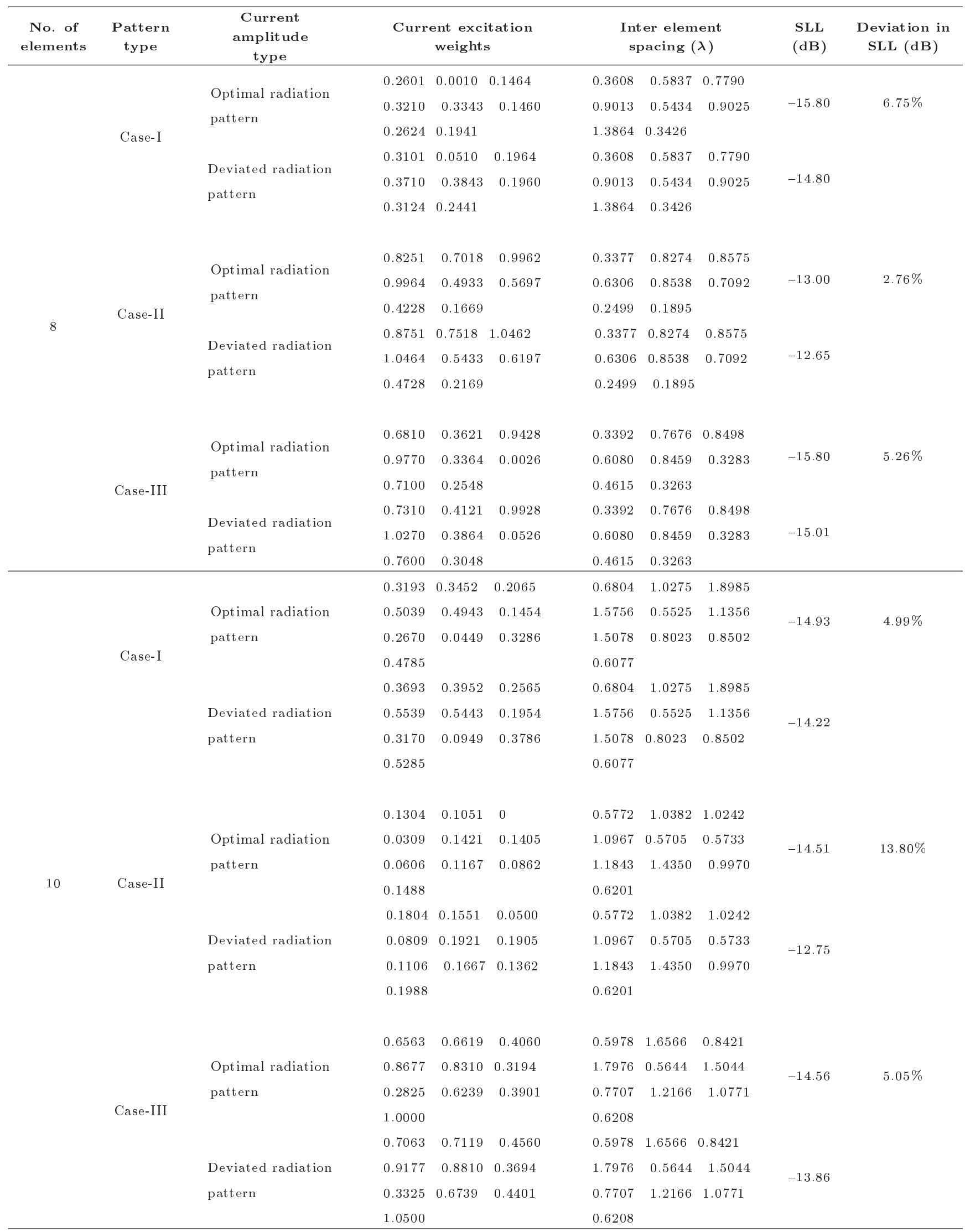


Table 9. Deviation of current amplitude excitation weights analysis with the fixed inter-element spacing obtained by using GWO algorithm for the synthesis of CDAA upon decreasing the current amplitude excitation in the second decimal.

\begin{tabular}{|c|c|c|c|c|c|c|c|c|c|c|}
\hline \multirow[t]{7}{*}{$\begin{array}{l}\text { No. of } \\
\text { elements }\end{array}$} & \multirow{7}{*}{$\begin{array}{c}\begin{array}{c}\text { Pattern } \\
\text { type }\end{array} \\
\text { Case-I }\end{array}$} & \multirow{4}{*}{$\begin{array}{l}\begin{array}{c}\text { Current } \\
\text { amplitude } \\
\text { type }\end{array} \\
\text { Optimal radiation } \\
\text { pattern }\end{array}$} & \multicolumn{3}{|c|}{$\begin{array}{c}\text { Current excitation } \\
\text { weights }\end{array}$} & \multicolumn{3}{|c|}{$\begin{array}{l}\text { Inter element } \\
\text { spacing }(\lambda)\end{array}$} & \multirow{3}{*}{$\begin{array}{r}\text { SLL } \\
(\mathrm{dB}) \\
-15.80\end{array}$} & \multirow{4}{*}{$\begin{array}{c}\begin{array}{c}\text { Deviation in } \\
\text { SLL (dB) }\end{array} \\
7.04 \%\end{array}$} \\
\hline & & & 0.2601 & 0.0010 & 0.1464 & 0.3608 & 0.5837 & 0.7790 & & \\
\hline & & & 0.3210 & 0.3343 & 0.1460 & 0.9013 & 0.5434 & 0.9025 & & \\
\hline & & & 0.2624 & 0.1941 & & 1.3864 & 0.3426 & & & \\
\hline & & & 0.2101 & -0.0490 & 0.0964 & 0.3608 & 0.5837 & 0.7790 & & \\
\hline & & Deviated radiation & 0.2710 & 0.2843 & 0.0960 & 0.9013 & 0.5434 & 0.9025 & -14.76 & \\
\hline & & patuen & 0.2124 & 0.1441 & & 1.3864 & 0.3426 & & & \\
\hline \multirow{12}{*}{8} & \multirow{6}{*}{ Case-II } & \multirow{3}{*}{$\begin{array}{l}\text { Optimal radiation } \\
\text { pattern }\end{array}$} & 0.8251 & 0.7018 & 0.9962 & 0.3377 & 0.8274 & 0.8575 & \multirow{3}{*}{-13.00} & \multirow{6}{*}{$1.88 \%$} \\
\hline & & & 0.9964 & 0.4933 & 0.5697 & 0.6306 & 0.8538 & 0.7092 & & \\
\hline & & & 0.4228 & 0.1669 & & 0.2499 & 0.1895 & & & \\
\hline & & \multirow{3}{*}{$\begin{array}{l}\text { Deviated radiation } \\
\text { pattern }\end{array}$} & 0.7751 & 0.6518 & 0.9462 & 0.3377 & 0.8274 & 0.8575 & \multirow{3}{*}{-12.76} & \\
\hline & & & 0.9464 & 0.4433 & 0.5197 & 0.6306 & 0.8538 & 0.7092 & & \\
\hline & & & 0.3728 & 0.1169 & & 0.2499 & 0.1895 & & & \\
\hline & \multirow{6}{*}{ Case-III } & \multirow{3}{*}{$\begin{array}{l}\text { Optimal radiation } \\
\text { pattern }\end{array}$} & 0.6810 & 0.3621 & 0.9428 & 0.3392 & 0.7676 & 0.8498 & \multirow{3}{*}{-15.80} & \multirow{6}{*}{$6.11 \%$} \\
\hline & & & 0.9770 & 0.3364 & 0.0026 & 0.6080 & 0.8459 & 0.3283 & & \\
\hline & & & 0.7100 & 0.2548 & & 0.4615 & 0.3263 & & & \\
\hline & & \multirow{3}{*}{$\begin{array}{l}\text { Deviated radiation } \\
\text { pattern }\end{array}$} & 0.6310 & 0.3121 & 0.8928 & 0.3392 & 0.7676 & 0.8498 & \multirow{3}{*}{-14.89} & \\
\hline & & & 0.9270 & 0.2864 & -0.0474 & 0.6080 & 0.8459 & 0.3283 & & \\
\hline & & & 0.6600 & 0.2048 & & 0.4615 & 0.3263 & & & \\
\hline \multirow{24}{*}{10} & \multirow{8}{*}{ Case-I } & & 0.3193 & 0.3452 & 0.2065 & 0.6804 & 1.0275 & 1.8985 & & \\
\hline & & Optimal radiation & 0.5039 & 0.4943 & 0.1454 & 1.5756 & 0.5525 & 1.1356 & -14.93 & $4.18 \%$ \\
\hline & & pattern & 0.2670 & 0.0449 & 0.3286 & 1.5078 & 0.8023 & 0.8502 & & \\
\hline & & & 0.4785 & & & 0.6077 & & & & \\
\hline & & & 0.2693 & 0.2952 & 0.1565 & 0.6804 & 1.0275 & 1.8985 & & \\
\hline & & Deviated radiation & 0.4539 & 0.4443 & 0.0954 & 1.5756 & 0.5525 & 1.1356 & -14.33 & \\
\hline & & pattern & 0.2170 & -0.0051 & 0.2786 & 1.5078 & 0.8023 & 0.8502 & & \\
\hline & & & 0.4285 & & & 0.6077 & & & & \\
\hline & & & 0.1304 & 0.1051 & 0 & 0.5772 & 1.0382 & 1.0242 & & \\
\hline & & Optimal radiation & 0.0309 & 0.1421 & 0.1405 & 1.0967 & 0.5705 & 0.5733 & -14.51 & $100.41 \%$ \\
\hline & & pattern & 0.0606 & 0.1167 & 0.0862 & 1.1843 & 1.4350 & 0.9970 & & \\
\hline & Case-II & & 0.1488 & & & 0.6201 & & & & \\
\hline & & & 0.0804 & 0.0551 & -0.0500 & 0.5772 & 1.0382 & 1.0242 & & \\
\hline & & Deviated radiation & -0.0191 & 0.0921 & 0.0905 & 1.0967 & 0.5705 & 0.5733 & -7.24 & \\
\hline & & pattern & 0.0106 & 0.0667 & 0.0362 & 1.1843 & 1.4350 & 0.9970 & & \\
\hline & & & 0.0988 & & & 0.6201 & & & & \\
\hline & & & 0.6563 & 0.6619 & 0.4060 & 0.5978 & 1.6566 & 0.8421 & & \\
\hline & & Optimal radiation & 0.8677 & 0.8310 & 0.3194 & 1.7976 & 0.5644 & 1.5044 & -14.56 & $1.11 \%$ \\
\hline & & pattern & 0.2825 & 0.6239 & 0.3901 & 0.7707 & 1.2166 & 1.0771 & & \\
\hline & Case-III & & 1.0000 & & & 0.6208 & & & & \\
\hline & & & 0.6063 & 0.6119 & 0.3560 & 0.5978 & 1.6566 & 0.8421 & & \\
\hline & & Deviated radiation & 0.8177 & 0.7810 & 0.2694 & 1.7976 & 0.5644 & 1.5044 & -14.40 & \\
\hline & & pattern & 0.2325 & 0.5739 & 0.3401 & 0.7707 & 1.2166 & 1.0771 & & \\
\hline & & & 0.9500 & & & 0.6208 & & & & \\
\hline
\end{tabular}




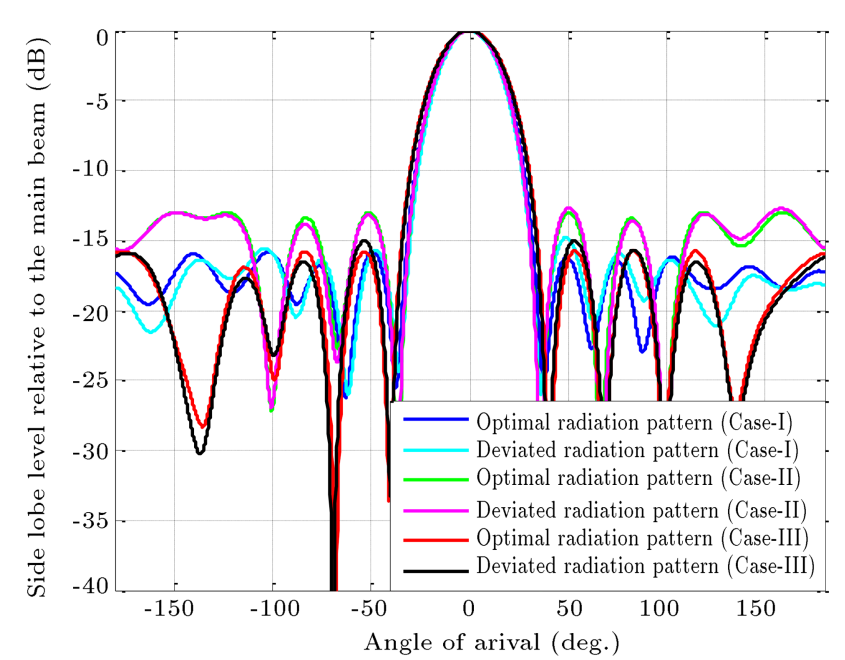

Figure 11. Deviation of current amplitude on radiation patterns of 8-element CDAA.

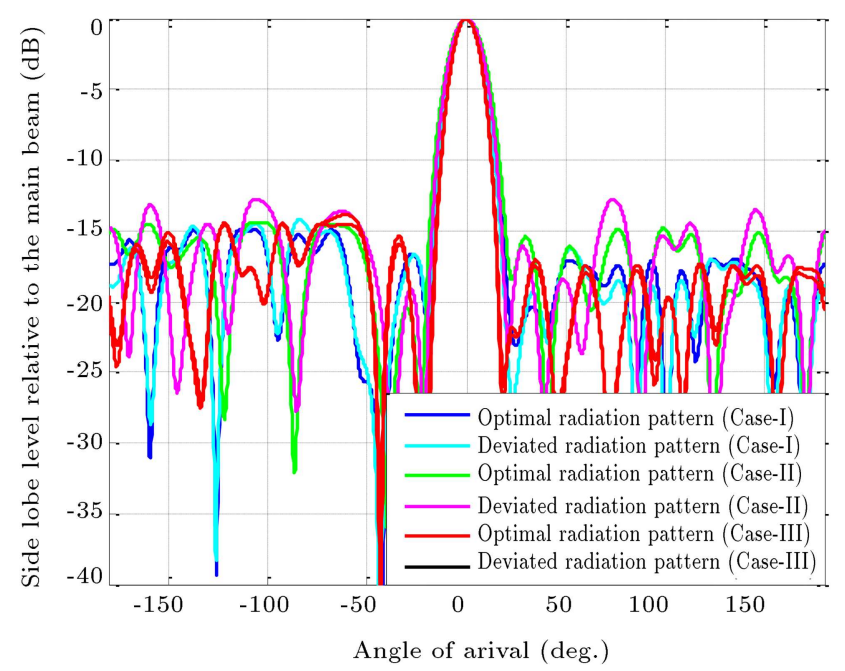

Figure 12. Deviation of current amplitude on radiation patterns of 10-element CDAA.

points with the decrement of 0.0500 , keeping the same inter-element spacing, as given in the optimal radiation pattern.

Figures 13 and 14 plot different cases (Case-I, Case-II, and Case-III) of the radiation pattern for the results as given in Table 9 to explore the effect of the deviation of the current amplitude excitation weights for the synthesis of 8-element and 10-element CDAAs by employing the GWO algorithm. The results show significant changes in maximum SLL by changing the current amplitude excitation weights at the second decimal points.

\subsection{Full wave simulation-based results}

The GWO algorithm-based results obtained by using parametric assimilation technique for the synthesis of 8- and 10-element CDAAs are validated in this paper by employing the Computer Simulation Technology Microwave Studio (CST-MS).

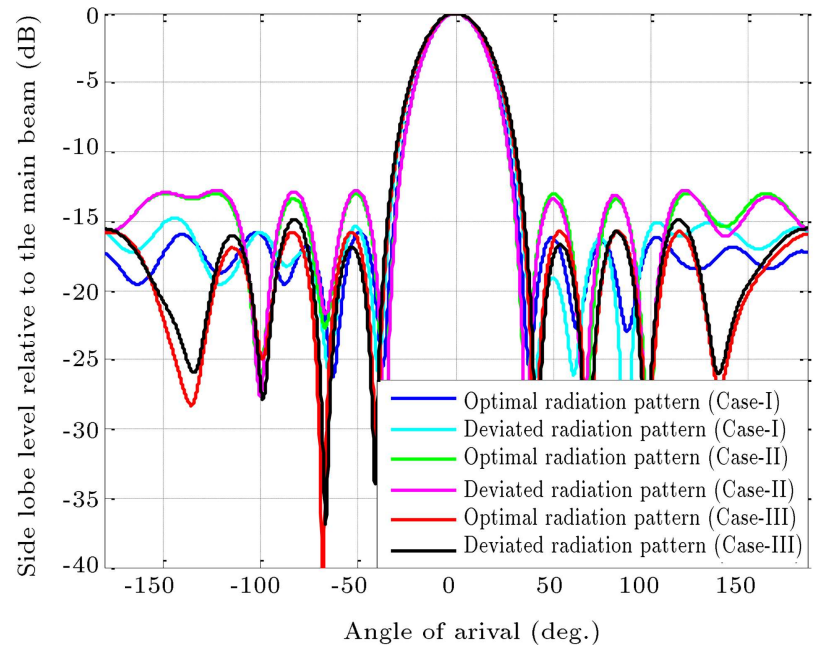

Figure 13. Deviation of current amplitude on radiation patterns of 8-element CDAA.

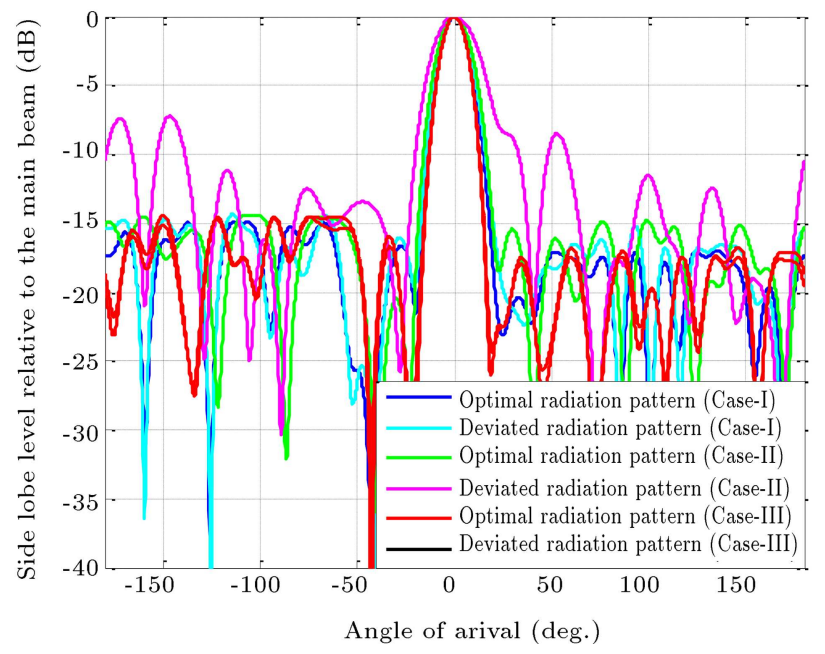

Figure 14. Deviation of current amplitude on radiation patterns of 10-element CDAA.

CST-MS is a widely used electromagnetic field simulation software product based on Finite Integration Technique (FIT), which can be applied from a low-frequency to high-frequency structure design.

Figures 15 and 16 show the designed half-wave dipole antenna and its far-field radiation pattern for the directivity calculation of the designed half-wave dipole antenna, respectively. Table 10 shows the design parameters of the half-wave dipole antenna and its simulated results obtained from CST-MS. The current amplitude excitation weights and the inter-element spacing values are the same as those of the computational results obtained by using GWO algorithm and parametric assimilation technique for the synthesis of 8- and 10-element CDAAs.

Table 10 shows the design parameters and the simulated results for 8- and 10-element CDAA synthesis by using CST-MS. The results show that the design parameters and the resonant frequency are of the same 
Table 10. Design parameters and the simulated results of CDAA obtained from CST-MS.

\begin{tabular}{|c|c|c|c|c|c|}
\hline \multirow{7}{*}{$\begin{array}{c}\text { No. of } \\
\text { elements }\end{array}$} & \multirow[t]{2}{*}{ Array type } & \multicolumn{2}{|c|}{ Design parameters of the CDAA } & \multicolumn{2}{|c|}{ Simulation results of the CDAA } \\
\hline & & Parameters & Values & Parameters & Values \\
\hline & & Length of dipole & $40.85 \mathrm{~mm}$ & Resonant frequency & $3.5 \mathrm{GHz}$ \\
\hline & & Resonant frequency & $3.5 \mathrm{GHz}$ & SLL & $-15.76 \mathrm{~dB}$ \\
\hline & Case-I & Feeding gap of antenna & $0.2042 \mathrm{~mm}$ & Directivity & $8.502 \mathrm{dBi}$ \\
\hline & & The radius of the wire & $0.085 \mathrm{~mm}$ & & \\
\hline & & Wavelength & $85 \mathrm{~mm}$ & & \\
\hline \multirow{15}{*}{8} & & Length of dipole & $40.85 \mathrm{~mm}$ & Resonant frequency & $3.5 \mathrm{GHz}$ \\
\hline & & Resonant frequency & $3.5 \mathrm{GHz}$ & SLL & $-12.89 \mathrm{~dB}$ \\
\hline & Case-II & Feeding gap of antenna & $0.2042 \mathrm{~mm}$ & Directivity & $8.133 \mathrm{dBi}$ \\
\hline & & The radius of the wire & $0.085 \mathrm{~mm}$ & & \\
\hline & & Wavelength & $85 \mathrm{~mm}$ & & \\
\hline & & Length of dipole & $40.85 \mathrm{~mm}$ & Resonant frequency & $3.5 \mathrm{GHz}$ \\
\hline & & Resonant frequency & $3.5 \mathrm{GHz}$ & SLL & $-15.92 \mathrm{~dB}$ \\
\hline & Case-III & Feeding gap of antenna & $0.2042 \mathrm{~mm}$ & Directivity & $8.424 \mathrm{dBi}$ \\
\hline & & The radius of the wire & $0.085 \mathrm{~mm}$ & & \\
\hline & & Wavelength & $85 \mathrm{~mm}$ & & \\
\hline & & Length of dipole & $40.85 \mathrm{~mm}$ & Resonant frequency & $3.5 \mathrm{GHz}$ \\
\hline & & Resonant frequency & $3.5 \mathrm{GHz}$ & SLL & $-15.01 \mathrm{~dB}$ \\
\hline & Case-I & Feeding gap of antenna & $0.2042 \mathrm{~mm}$ & Directivity & $9.525 \mathrm{~dB}$ \\
\hline & & The radius of the wire & $0.085 \mathrm{~mm}$ & & \\
\hline & & Wavelength & $85 \mathrm{~mm}$ & & \\
\hline \multirow{10}{*}{10} & & Length of dipole & $40.85 \mathrm{~mm}$ & Resonant frequency & $3.5 \mathrm{GHz}$ \\
\hline & & Resonant frequency & $3.5 \mathrm{GHz}$ & SLL & $-14.48 \mathrm{~dB}$ \\
\hline & Case-II & Feeding gap of antenna & $0.2042 \mathrm{~mm}$ & Directivity & $9.461 \mathrm{dBi}$ \\
\hline & & The radius of the wire & $0.085 \mathrm{~mm}$ & & \\
\hline & & Wavelength & $85 \mathrm{~mm}$ & & \\
\hline & & Length of dipole & $40.85 \mathrm{~mm}$ & Resonant frequency & $3.5 \mathrm{GHz}$ \\
\hline & & Resonant frequency & $3.5 \mathrm{GHz}$ & SLL & $-14.62 \mathrm{~dB}$ \\
\hline & Case-III & Feeding gap of antenna & $0.2042 \mathrm{~mm}$ & Directivity & $9.776 \mathrm{dBi}$ \\
\hline & & The radius of the wire & $0.085 \mathrm{~mm}$ & & \\
\hline & & Wavelength & $85 \mathrm{~mm}$ & & \\
\hline
\end{tabular}

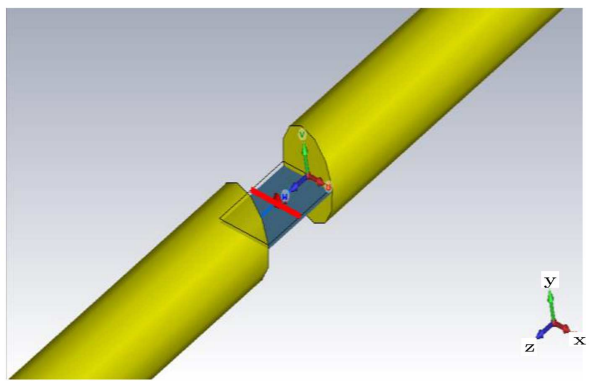

Figure 15. Designed half-wave dipole antenna.

value for all the cases of 8- and 10-element CDAA design, whereas the SLL and directivity values are changed for different cases of 8- and 10-element CDAA designs. The simulated results of Table 10 obtained by using CST-MS validate the results achieved by using GWO algorithm for the synthesis of 8- and 10element CDAAs through the parametric assimilation technique.

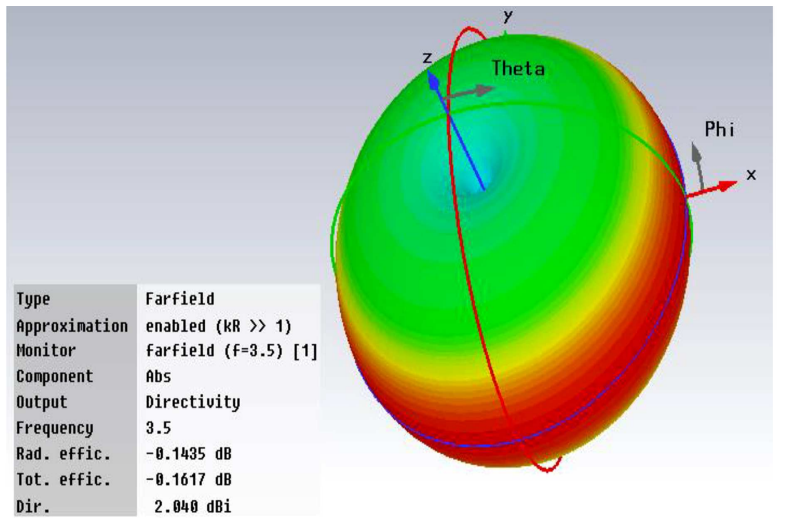

Figure 16. The far-field radiation pattern of the designed half-wave dipole antenna.

Figures 17, 18, and 19 show the far-field radiation pattern of 8-element CDAA obtained by using CSTMS for Case-I, Case-II, and Case-III, respectively. The directivity and SLL values obtained for different cases 


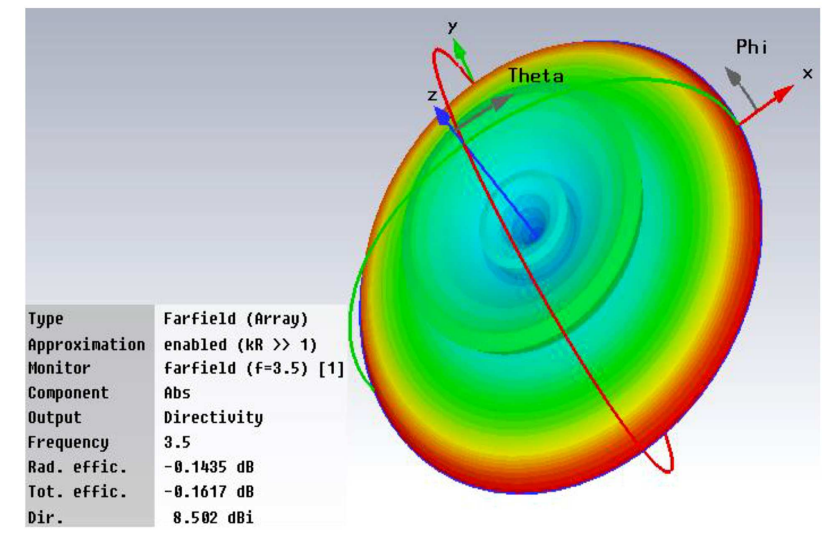

Figure 17. The far-field radiation pattern of 8-element CDAA obtained by CST-MS for Case-I.

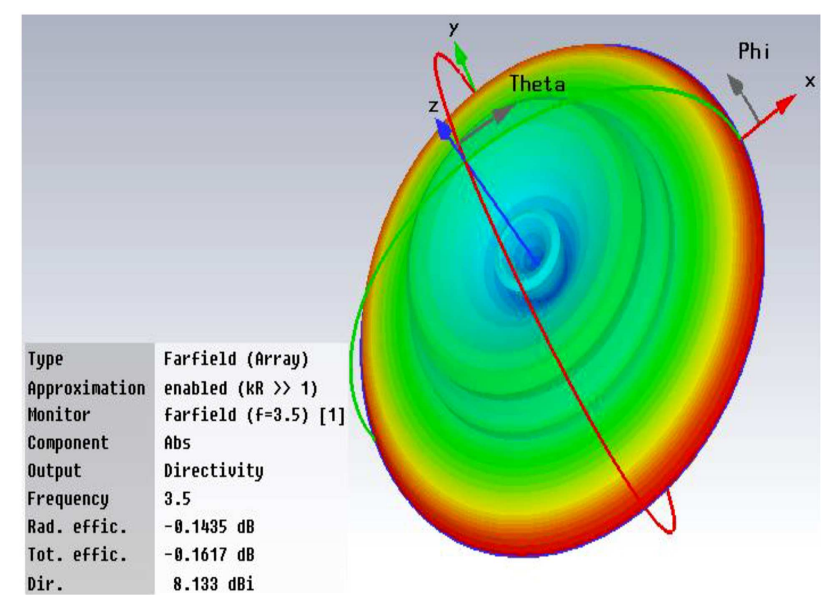

Figure 18. The far-field radiation pattern of 8-element CDAA obtained by CST-MS for Case-II.

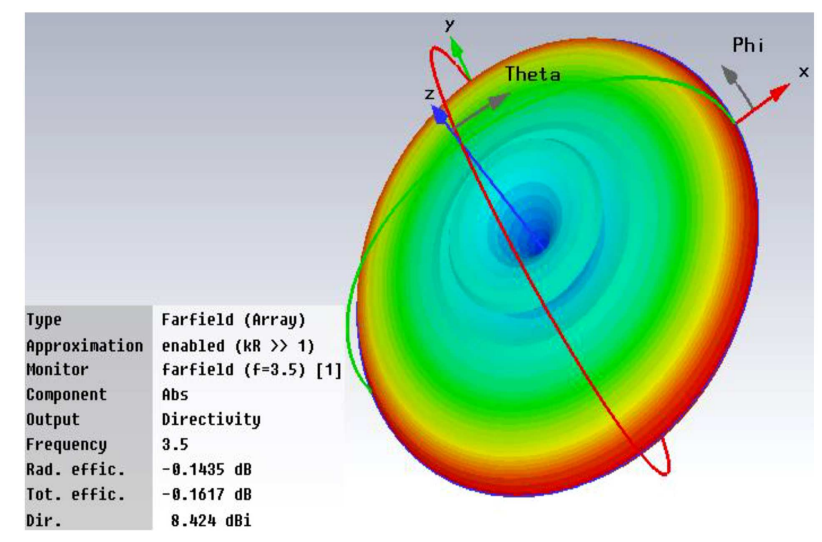

Figure 19. The far-field radiation pattern of 8-element CDAA obtained by CST-MS for Case-III.

of 8-element CDAA design by using CST-MS are given in Table 10.

Figure 20 shows the far-field radiation pattern in a Cartesian plot for 8-element CDAA design by using CST-MS for different cases (Case-I, Case-II, and CaseIII). Figure 20 shows the maximum SLL values for

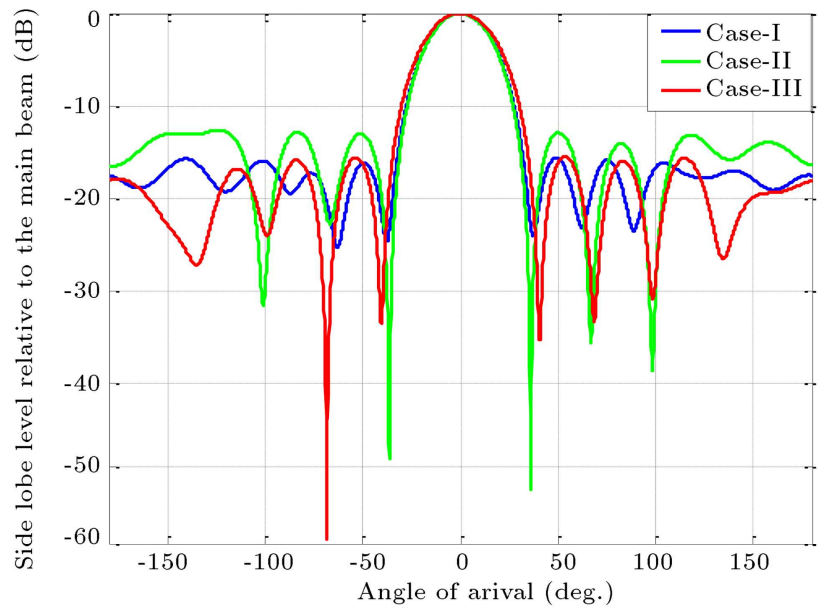

Figure 20. The far-field radiation pattern of 8-element CDAA obtained by using CST-MS for different cases.

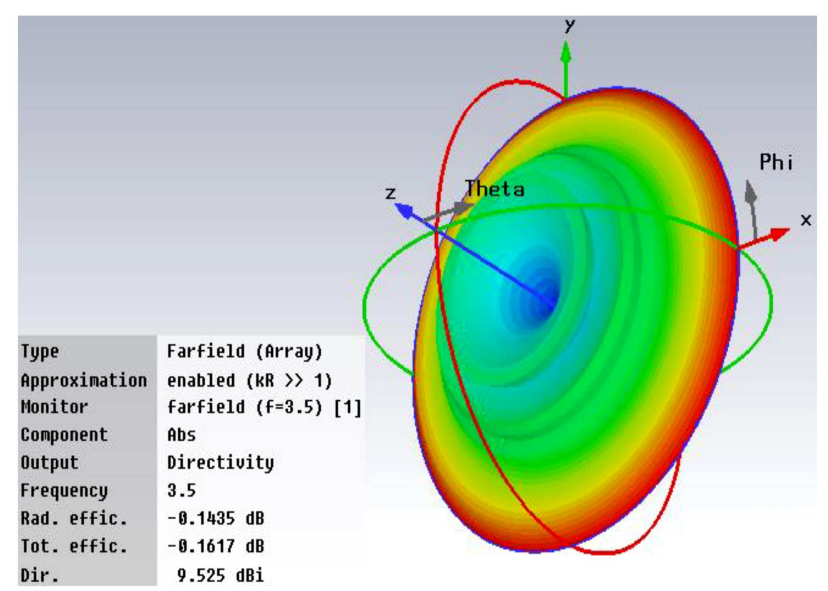

Figure 21. The far-field radiation pattern of 10-element CDAA obtained by CST-MS for Case-I.

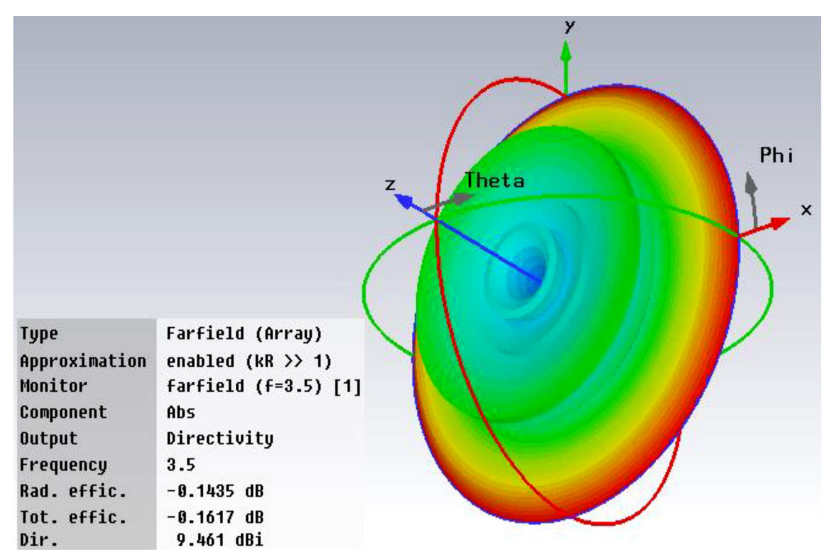

Figure 22. The far-field radiation pattern of 10-element CDAA obtained by CST-MS for Case-II.

Case-I, Case-II, and Case-III which validate the GWO algorithm-based results for 8- element CDAA synthesis.

The far-field radiation patterns for the design of 10- element CDAA by using CST-MS for Case-I, Case-II, and Case-III are shown in Figures 21, 22, 


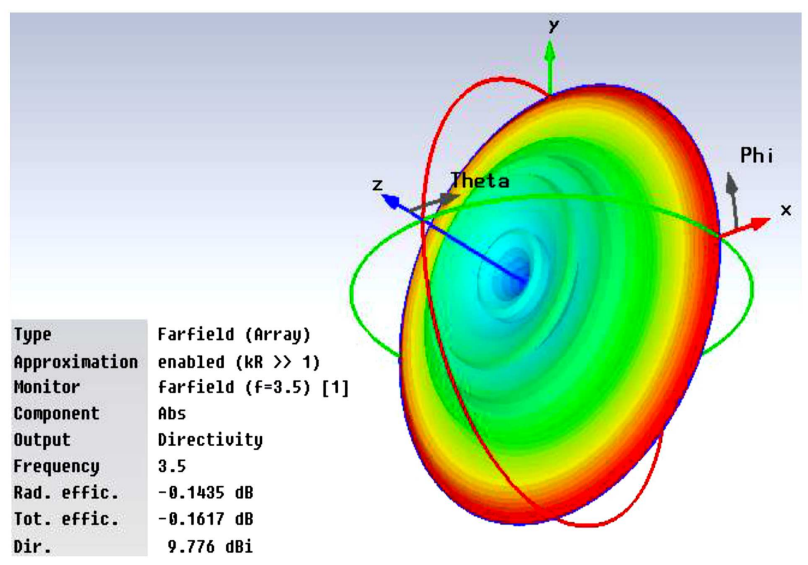

Figure 23. The far-field radiation pattern of 10-element CDAA obtained by CST-MS for Case-III.

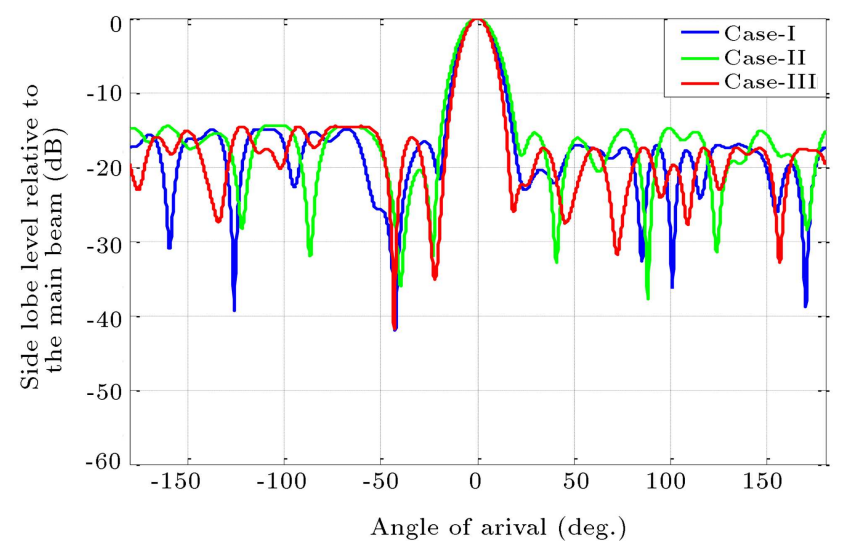

Figure 24. The far-field radiation pattern of 10-element CDAA obtained by using CST-MS for different cases.

and 23, respectively, to validate the GWO algorithmbased results for the synthesis of 10-element CAA. The directivity achieved using different cases for these designs is given in Table 10 .

Figure 24 shows the Cartesian plots of the farfield radiation pattern of 10 -element CDAA obtained by using CST-MS for Case-I, Case-II, and Case-III to validate the results achieved by GWO for the synthesis of 10-element CDAA. The maximum SLL values achieved for the design of 10-element CDAA of different cases are given in Table 10 and they also validate the CST-MS-based results with respect to the results obtained through GWO for the synthesis of 10element CDAA.

\subsection{Convergence profile plots of different algorithms achieved by using parametric assimilation technique}

The minimum $\mathrm{CF}$ values against the number of iteration cycles are recorded to get the convergence profile. Figures 25 and 26 show the convergence plots of the 8- and 10-element CDAA designs using PSO, DE, and GWO algorithms for the corrected

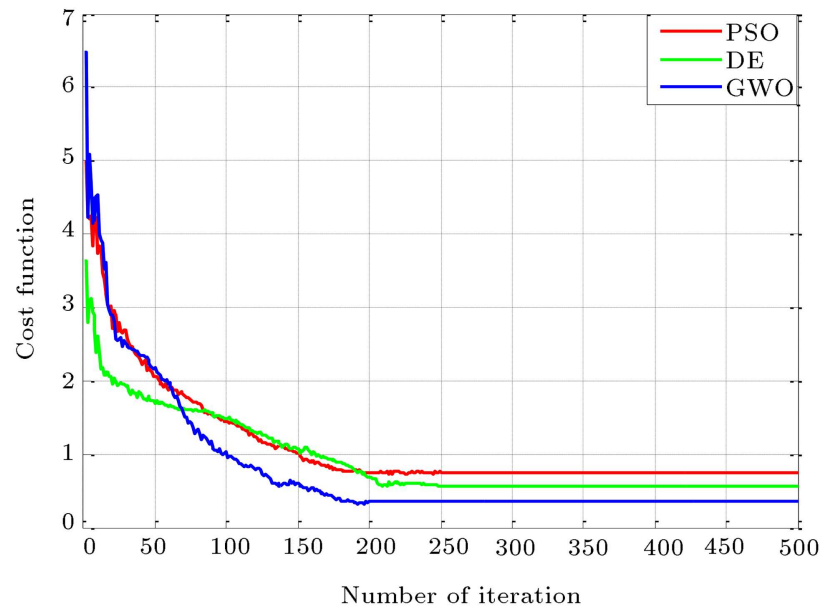

Figure 25. Convergence profile of 8-element CDAA.

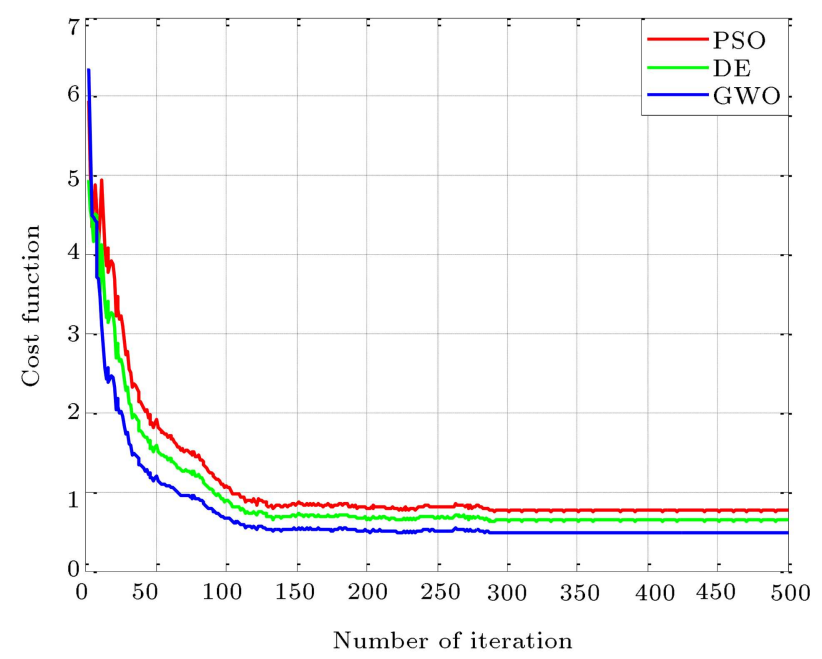

Figure 26. Convergence profile of 10-element CDAA.

radiation pattern (Case-III) synthesis achieved by using parametric assimilation technique.

Figures 25 and 26 confirm the excellent optimizing capability of GWO algorithm in terms of precision and convergence speed for 8- and 10-element CDAA synthesis using parametric assimilation technique.

\section{Conclusion}

In this paper, the Grey Wolf Optimization (GWO) technique was applied for the solution of highly non-linear values of the current amplitude excitation weights and inter-element spacing for the circular dipole antenna array synthesis using the parametric assimilation technique to correct mutual coupling affected erred radiation pattern nearly equal to the form of the desired radiation pattern. The desired pattern was obtained without considering the mutual coupling effect for the circular dipole antenna array synthesis using different optimization techniques. This study investigated the problem of designing CDAA consid- 
ering the mutual coupling effect and the correction of uncorrected erred radiation pattern using parametric assimilation using different optimization techniques. The main objective of this work was to correct the mutual coupling affected erred radiation pattern. The results obtained by using different optimization techniques show that the parametric assimilation technique has an excellent prospect to be used for the correction of the mutual coupling affected radiation pattern. Some well-established algorithms including PSO and DE optimization techniques were also applied here to establish the superiority of GWO algorithmbased results. The results demonstrated that GWO algorithm yielded an improved CDAA design in terms of the erred radiation pattern correction into the form of the desired radiation pattern. Thus, GWO has an excellent potential to be used as an efficient optimizer to design a circular dipole antenna array considering the mutual coupling effect.

\section{Acknowledgement}

This work was funded by the Science \& Engineering Research Board (SERB), Department of Science \& Technology-Government of India under the grant EEQ/2017/000519 dated 23 March 2018. The authors are grateful to the Science and Engineering Research Board for funding the project and Visvesvaraya $\mathrm{PhD}$ Scheme, Ministry of Electronics and IT, Government of India.

\section{References}

1. Ballanis, C.A., Antenna Theory Analysis and Design, 2nd Edition, John Willey and Son's Inc, New York (1997).

2. Elliott, R.S., Antenna Theory and Design, Revised Edition, John Willey, NJ (2003).

3. Collin, R.E., Antenna and Radio Wave Propagation, McGraw-Hill, New York (1985).

4. Sharaqa, A. and Dib, N. "Circular antenna array synthesis using firefly algorithm", International Journal of RF and Microwave Computer-Aided Engineering, 24(2), pp. 139-146 (2014).

5. Das, A., Mandal, D., Ghoshal, S.P., et al. "Moth flame optimization-based design of linear and circular antenna array for sidelobe reduction", International Journal of Numerical Modelling, 32(1), pp. 1-15 (2018).

6. Das, A., Mandal, D., Ghoshal, S.P., et al. "A heuristic approach to design linear and circular antenna array for side lobe reduction", Iranian Journal of Science and Technology Transaction of Electrical Engineering, 43(1), pp. 67-76 (2018).

7. Singh, U. and Kamal, T.S. "Design of non-uniform circular antenna arrays using biogeography-based op- timization", IET Microwaves Antennas and Propagation, 5(11), pp. 1365-1370 (2011).

8. Guney, K. and Basbug, S. "A parallel implementation of seeker optimization algorithm for designing circular and concentric circular antenna arrays", Applied Soft Computing, 22, pp. 287-296 (2014).

9. Rattan, M., Patterh, M.S., and Sohi, B.S. "Optimization of circular antenna arrays of isotropic radiators using simulated annealing", International Journal of Microwave and Wireless Technologies, 1(5), pp. 441446 (2009).

10. Shihab, M., Najjar, Y., and Khodier, NDM. "Design of non-uniform circular antenna arrays using particle swarm optimization", Journal of Electrical Engineering, 59(4), pp. 216-220 (2008).

11. Chakravorty, P. and Mandal, D. "Radiation pattern correction in mutually coupled antenna arrays using parametric assimilation technique", IEEE Transactions on Antennas and Propagation, 64(9), pp. 40924095 (2016).

12. Das, A., Mandal, D., Ghoshal, S.P., et al. "An efficient side lobe reduction technique considering mutual coupling effect in linear array antenna using BAT algorithm", Swarm and Evolutionary Computation, 35, pp. 26-40 (2017).

13. Singh, H., Sneha, H.L., and Jha, R.M. "Mutual coupling in phased arrays: A review", International Journal of Antennas and Propagation, 2013, pp. 1-23 (2013).

14. Gupta, I.J. and Ksienski, A.A. "Effect of mutual coupling on the performance of adaptive arrays", IEEE Transactions on Antennas and Propagation, 31(5), pp. 785-791 (1983).

15. Salonen, I., Toropainen, A., and Vainikainen, P. "Linear pattern correction in a small microstrip antenna array", IEEE Transactions on Antennas Propagation, 52, pp. 578-586 (2004).

16. Kang, Y.W. and Pozar, D.M. "Correction of error in reduced sidelobe synthesis due to mutual coupling", IEEE Transaction on Antennas and Propagation, 33(9), pp. 1025-1028 (1985).

17. Kelley, D.F. and Stutzman, W.L. "Array antenna pattern modeling methods that include mutual coupling effects", IEEE Transactions on Antennas and Propagation, 41(12), pp. 1625-1632 (1993).

18. Kennedy, J. and Eberhart, R. "Particle swarm optimization", Proceeding of IEEE International Conference on Neural Network, 4, pp. 1942-1948 (1995).

19. Eberhart, R. and Shi, Y. "Comparison between genetic algorithm and particle swarm optimization", in Evolutionary Programming VII, Springer, pp. 611-616 (1998). 
20. Robinson, J. and Rahmat-Samii, Y. "Particle swarm optimization in electromagnetics", IEEE Transaction on Antenna Propagation, 52(2) pp. 397-407 (2004).

21. Storn, R. and Price, K. "Differential evolution- a simple and efficient adaptive scheme for global optimization over continuous spaces", Technical Report, International Computer science Institute, Berkley (1995).

22. Karaboga, N. "Digital IIR filter design using differential evolution algorithm", EURASIP Journal on Applied Signal Processing, 2005, Article ID 8, pp. 1269-1276 (2005).

23. Mirjalili, S., Mirjalili, S.M., and Lewis, A. "Grey wolf optimizer", Advances in Engineering Software, 69, pp. 46-61 (2014).

24. Saxena, P. and Kothari, A. "Optimal pattern synthesis of linear antenna array using grey wolf optimization algorithm", International Journal of Antennas and Propagation, 2016, Article ID 1205970 (2016).

25. Das, A., Mandal, D., Ghoshal, S.P., et al. "Concentric circular antenna array synthesis for sidelobe suppression using moth flame optimization", International Journal of Electronics and Communication (AEU), 86, pp. 177-184 (2018).

26. Das, A., Mandal, D., and Kar, R. "An optimal far-field radiation pattern synthesis of time modulated linear and concentric circular antenna array", International Journal of Numerical Modelling-Electronic Networks, Devices and Fields, 32(6), pp. 1-20 (2019).

27. Das, A., Mandal, D., Ghoshal, S.P. et al. "An optimal mutually coupled concentric circular antenna array synthesis using ant lion optimization", Annals of Telecommunication, 74(11-12), pp. 687-696 (2019).

28. Ram, G., Mandal, D., Kar, R., et al. "Circular and concentric circular antenna array synthesis using cat swarm optimization", IETE Technical Review, 32(3), pp. 204-217 (2015).

29. Babayigit, B. and Senyigit, E. "Design optimization of circular antenna arrays using Taguchi method", Neural Computing and Application, 28(6), pp. 14431452 (2017).

30. Ram, G., Mandal, D., Kar, R., et al. "Oppositionbased gravitational search algorithm for synthesis circular and concentric circular antenna array", Scientia Iranica D, 22(6), pp. 2457-2471 (2015).

31. Ram, G., Mandal, D., Kar, R., et al. "Improvement in various radiation characteristics of time modulated linear antenna arrays using evolutionary algorithms", Journal of Experimental and Theoretical Artificial Intelligence, 28(1-2), pp. 151-180 (2016).

32. Ram, G., Mandal, D., Kar, R., et al. "Pencil beam pattern synthesis of time-modulated concentric circular antenna array using PSO with aging leader and challenger", Journal of Electromagnetic Waves and Applications, 29(12), pp. 1610-1629 (2015).
33. Ram, G., Mandal, D., Ghoshal, S.P., et al. "Optimization of radiation characteristics of time modulated circular geometry using DEWM", Scientia Iranica D, 25(3), pp. 1571-1581 (2018).

34. Mahata, S., Saha, S.K., and Kar, R., et al. "Optimal design of fractional-order digital integrators: An evolutionary approach", Scientia Iranica D, 25(6), pp. 3604-3627 (2018).

35. Walpole, R.E. and Myer, R.H., Probability and Statistics for Engineers and Scientists, New York, Macmillan (1978).

\section{Biographies}

Avishek Das completed his BE degree in Electronics and Communication Engineering and MTech (the project was done on Microwave at Antenna Division in SAMEER-Centre for Electromagnetics, Chennai) in E.C.E (Microwave) from The University of Burdwan, West Bengal, India in 2008 and 2010, respectively. He received an MBA degree in Human Resource from Sikkim Manipal University in 2014 and completed his PhD degree in 2020 from National Institute of Technology, Durgapur, West Bengal, India under Visvesvaraya PhD Scheme for Electronics and IT, Ministry of Electronics and IT, Government of India. Presently, he is working as an Assistant Professor at the Department of Electronics and Communication Engineering, Haldia Institute of Technology, Haldia, West Bengal, India and associated as a post $\mathrm{PhD}$ researcher at National Institute of Technology, Durgapur on the project funded by Science and Engineering Research Board, Department of Science and Technology, Government of India (Grant No. EEQ/2017/000519 dated 23/03/2018). His research interests include the application of evolutionary optimization techniques for the design of antenna arrays.

Durbadal Mandal passed BE degree in Electronics and Communication Engineering, from Regional Engineering College, Durgapur, West Bengal, India in the year 1996. He received the MTech and PhD degrees from National Institute of Technology, Durgapur, West Bengal, India in 2008 and 2011, respectively. Presently, he is working in National Institute of Technology, Durgapur, West Bengal, India as an Associate Professor at the Department of Electronics and Communication Engineering. His research interests include array antenna design and filter optimization via evolutionary computing techniques. He has published more than 350 research papers in international journals and conferences.

Rajib Kar received BE degree in Electronics and Communication Engineering, from Regional Engineering College, Durgapur, West Bengal, India in 2001. He 
received the MTech and $\mathrm{PhD}$ degrees from National Institute of Technology, Durgapur, West Bengal, India in 2008 and 2011, respectively. Presently, he is working in National Institute of Technology, Durgapur, West Bengal, India as an Associate Professor at the Depart- ment of Electronics and Communication Engineering. His research interests include VLSI circuit optimization and signal processing using evolutionary computing techniques. He has published more than 350 research papers in international journals and conferences. 